\title{
الوسطية الفكرية وأثرها في الحوار الحضاري المعاصر
}

\section{إعداد الدكتور \\ علي بن دخيل الله بن دخيل الصاعدي}

أستاذ مساعد، قسم الدراسات الإسلامية، جامعة تبوك فرع أملج 

الوبطية الفكرية وأثرها في الحوار الحضاري المعاصر

علي بن دخيل الله بن دخيل الصاعدي

قسم الاراسات الإسدلامية، جامعة تبوك فرع أملج - المملكة العربية السعودية.

$$
\text { البريد الإلكتروني: aalsaedi@ut.edu.sa }
$$

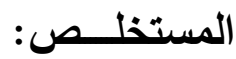

تهدف هذه الدراسات إلى بيان مفهوم الوسطية الفكرية، والحوار الحضاري، والتأصيل الثرعي للوسطية الفكرية في الحوار الحضاري المعاصر، وبيان أهم الأسس والمرنكزات للحوار الحضاري، ومن ثم بيان أهمية هذه الوسطية في الحوار الحضاري المعاصر، كما بينت هذه الدراسة ضوابط هذه الوسطية ومظاهرها والآثار الإيجابية التي تتتج عن تطبيقها على مستوى الفرد والمجتمعات. كلمات مفتاحية: (الحضارة، الفكر، الاعتدال، النتائج، الإيجابية). 
الوسطية الفكرية وأثرها في الحوار الحضاري المعاصرح

Intellectual moderation and its impact on contemporary

civilizational dialogue

\author{
Ali Dakhil Allah Dakhil Al-Saedi \\ of Islamic Studies, University of Tabuk, Umluj of Saudi \\ Arabia.
}

Email: aalsaedi@ut.edu.sa

\title{
Abstract:
}

These studies aim to clarify the concept of intellectual moderation, civilized dialogue, and the legitimate rooting of intellectual moderation in contemporary civilizational dialogue, and to clarify the most important foundations and foundations for civilized dialogue, and then to explain the importance of this moderation in contemporary civilizational dialogue. It results from its application at the individual and community level.

Keywords:(civilization, thought, moderation, results, positivity).

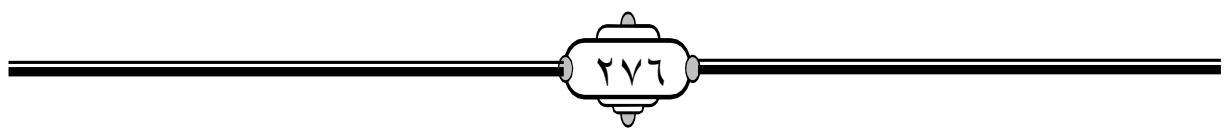




\section{المقدمـة}

إن الحمد لله نحمده ونستعينه ونستغفره، ونعوذ بالله من شرور أنفسنا ومن سيئات أعمالنا من يهده الله فلا مضل له، ومن يضلل فلا هادي له، وأشهد ألا إله إلا الله وحده لا شربك له، وأثهد أن محمدا عبده ورسوله عليولسلم وعلى آله وصحبه

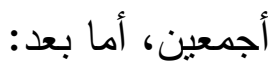

\section{أهمية الموضوع وسبب اختياره:}

يعد الحوار من أهم أسس الحياة في العلاقات الاجتماعية والسياسية والتقافية والفكرية بين البشر، وهو لغة التفاهم والتواصل التي تتيح للفرد حرية التعبير عن حاجاته ورغباته ومشاعره، ولذلك فإن قضية الحوار أصبحت من القضايا والموضوعات الهامة لكل المشكلات العالقة في عصرنا الراهن سواء على المستوى الداخلي في المجتمع الواحد، أو على المستوى الخارجي مع الحضارات والتقافات الأخرى، وهو مطلب للإنسانية جمعاء، والمنهج الصحيح للتفاهم والتعايش والتواصل بين الأمم والثعوب، ولكي يؤتي هذا الحوار ثماره المرجوة منه والمبتغى المراد، لا بد أن يكون قائم على الوسطية والاعتدال لا سيما في هذه العصور المتقدمة التي أصبح العالم فيها قرية صغيره بسبب التقنيات الحديثة التي وصل إلبها الإنسان في عصرنا الحديث من قنوات فضائية، وشبكه الإنترنت وهواتق نقاله، لذا كان من المهر اتباع المنهج السليم في الحوار القائم على الوسطية والاعتدال النابعة من مبادئ الدين الحنيف والهدى النبوي.

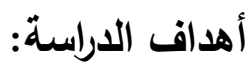

تكمن أهداف الدراسة في النقاط التالية: أولاً: بيان مفهوم الوسطية الفكرية في الإسلام، وأهميتها. ثانياً: بيان مفهوم الحوار الحضاري في الإسلام.

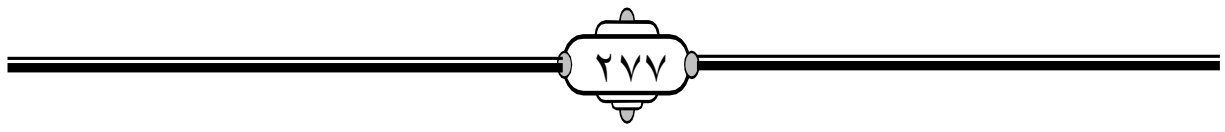


ثالثاً: التأصيل الثرعي للوسطية الفكرية في الحوار الحضاري رابعاً: بيان أسس ومرتكزات الحوار الحضاري.

خامساً: إلقاء الضوء على آثار الوسطية الفكرية في الحوار الحضاري. سادساً: بيان ضوابط الوسطية الفكرية في الحوار الحضاري ومظاهرها.

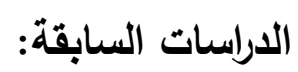

لم أقف- حتى كتابة هذا البحث- على دراسة علمية تتاولت هذا الموضوع

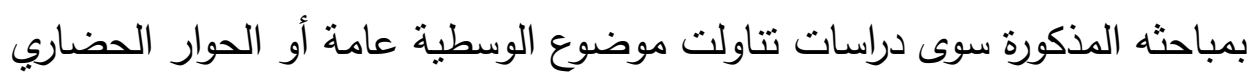
دون التطرق للوسطية الفكرية في الحوار الحضاري المعاصر على وجه الخصوص. ثالثثاً: تقسيم الدراسة: اشتملت خطة الدراسة على مقدمة وتمهيد ومبحثين وخاتمة وهي على النحو التالي:

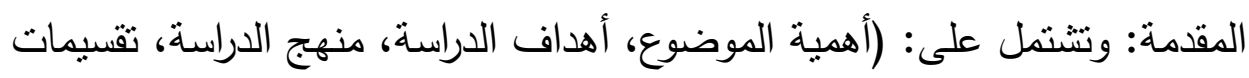
الدراسة). التمهي⿻: ويشتمل على مطالبين: المطلب الأول: مفهوم الوسطية الفكرية المطلب الثاني: مفهوم الحوار الحضاري المبحث الأول: الوسطية الفكرية في الحوار الحضاري. ويشتمل على ثلاثة مطالب: المطلب الأول: التأصيل الثرعي للوسطية الفكرية في الحوار الحضاري. المطلب الثاني: أصول وأسس الحوار الحضاري. المطلب الثالث: أهمية الوسطية الفكرية في الحوار الحضاري. المبحث الثاني: مظاهر الوسطية الفكرية في الحوار الحضاري وآثارها. ويشتمل على ثلاثة مطالب:

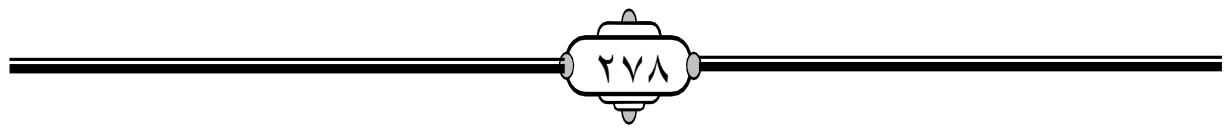


المطلب الأول: ضوابط الوسطية الفكربة في الحوار الحضاري. المطلب الثاني: مظاهر الوسطية الفكرية في الحوار الحضاري. المطلب الثالث: آثار الوسطية الفكرية في الحوار الحضاري. الخاتمة: ونتنمل على ما يأني: $\checkmark$

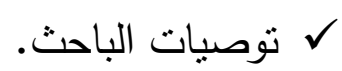

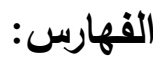
ا ـ فهرس المصادر والمراجع. r ب . فهرس الموضوعات. رابعاً: منهج الدراسة.

نظرا لكون الدراسة جمعت ما بين العرض والتحليل، فقد استخدم الباحث المنهج الوصفي الاستقرائي، والمنهج التحليلي، وذلك بتتبع وجمع الوقائع والأحداث، ومن ث دراستها.

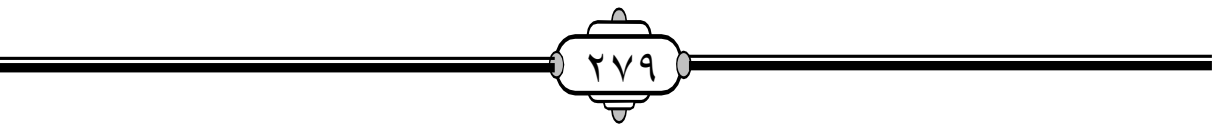




\section{التمهيد \\ المطلب الأول \\ مفهوم الوسطية الفكرية}

أولاً: الوسطية في اللغة: مأخوذة من (وسط)، وسَطُ الثيء ما بين طرَفَيَه،

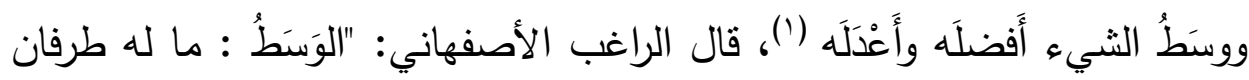
مُتساوِيَا القدر ، ويقال ذلك في الكمية المُنََّلة؛؛ كالجسم الواحد ... ووَسْط بالسكون، يقال في الكمية المُنفصلة، كثيء يَفصل بين جسمين، نحو: وَسْطُ القوم كذا، والوَسَط تارة يقال فيما له طََفَان مذمومان؛ يقال: "هذا أوسطهم حَسَبًا"، إذا كان في هي

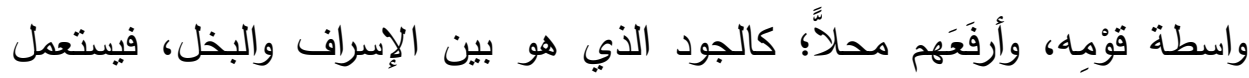
استعمال القصد المصون عن الإفراط والتَّزْيط، فيمدح به نحو: السواء، والعدل،

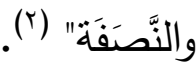

\section{الوسطية في الاصطلاح:}

لا يختلف المعنى الاصطلاحي للوسطية عن المعنى اللغوي، فقد وردت في

القرآن والسنة النبوية على معاني عدة ولعل من أهم هذه المعاني وأبرزها ما يلي: فقد تأتي بمعنى العدل والخيرية والتوسط بين الإفراط والتقريط ومن ذلك قوله تعالى:

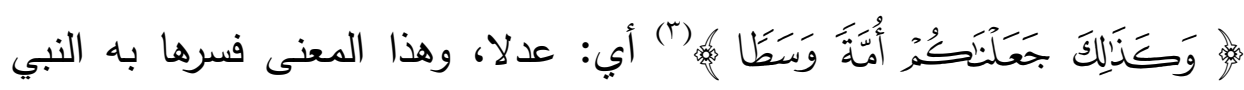
عليلوسلم في حديث أبي سعيد الخدري رضى الله عنه فقال: "الوسط: العدل" (ء). وقال ابن جرير الطبري رحمه الله أنها بمعنى التوسط بين الإفراط والتقريط فقال: " وأرى أن اله تعالى ذكره إنما وصفهم بأنهم "وسط"، لتوسطهم في الدين، فلا

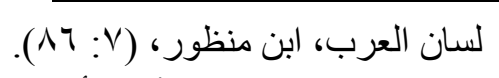

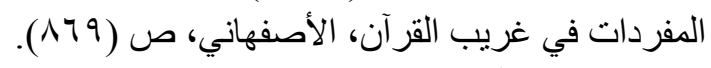

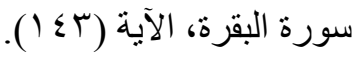

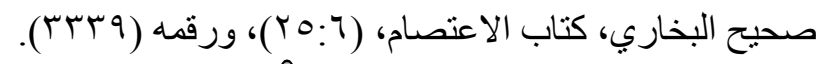

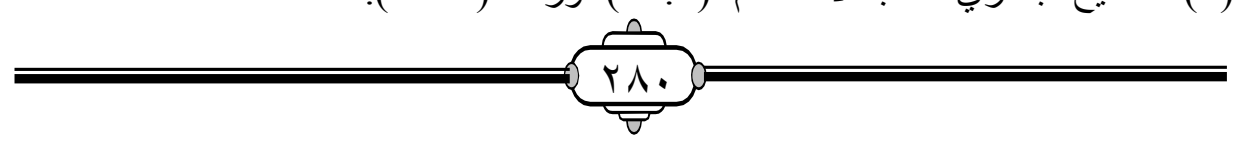


هم أهل غلو فيه، غلو النصارى الذين غلوا بالترهب، وقولهم في عيسى ما قالوا فيه - ولا هم أهل تقصير فيه، تقصير اليهود الذين بدلوا كتاب الله، وقتلوا أنبياءهم، وكذبوا على ربهم، وكفروا به؛ ولكنهم أهل توسط واعتدال فيه، فوصفهم الله بذلك، إذ كان أحب الأمور إلى الله أوسطها" (')، كما فسرها ابن كثثر رحمه الله فقال: "والوسط هاهنا: الخيار والأجود" (؟).

فالوسطية في الإسلام" وسط بين من غلا في أمر الدنيا ولم يهتم بالآخرة، وبين من غلا في أمر الآخرة ونظر إلى الدنيا نظرة ازدراء وابتعاد، وهكذا الوسطية تؤدي الي التوازن الظاهر بين الدين والدنيا، وبين النقل والعقل وبين مطالب البدن ومطالب الروح، وبين علم الغيب وعلم الثهادة، فلقد ساد الوسطية بهذا المفهوم في

الفكر الإسلامي في العقيدة والتشريع والعبادة والدعوة إلى الله تعالى" (r). ثانيا: الفكر في اللغةة: مأخوذ من مادة "فَّكَ رَ"، التي هي تردد القلب وتأمله،

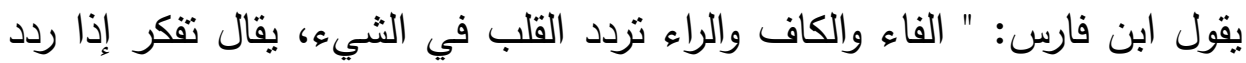

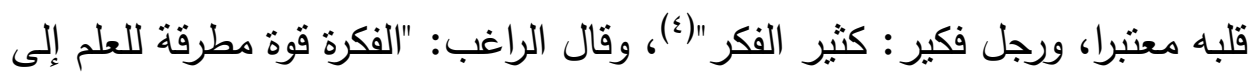
المعلوم، والتفكر جولان تلك القوة بحسب نظر العقل وذللك للإنسان دون الحيوان"(0). (المعوم،

القكر في الاصطلاح: يقال:" الفكر ترتيب أمور في الذهن يتوصل بها إلى

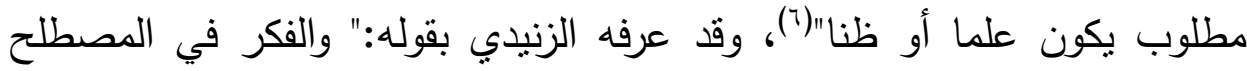
الفكري -والفلسفي خاصة- هو الفعل الذي تقوم به النفس عند حركتها في

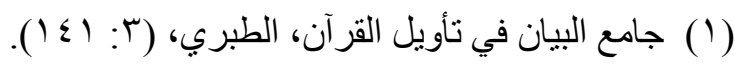

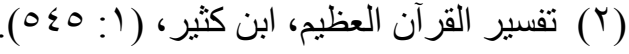

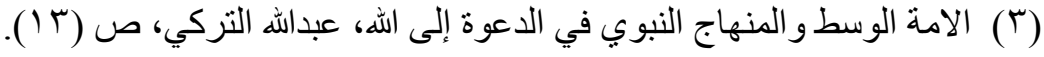

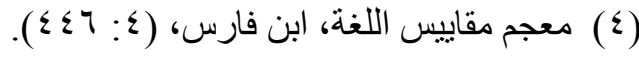

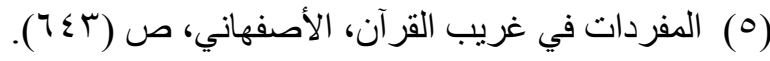

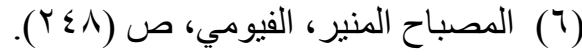

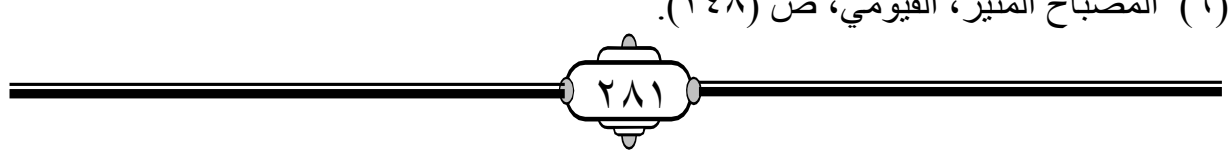




\section{الوسطية الفكرية وأثرها في الحوار الحضاري الععاصرل}

المعقولات، أب النظر والتأمل والتدبر والاستتباط والحكم، ونحو ذلك. وهو كذلك

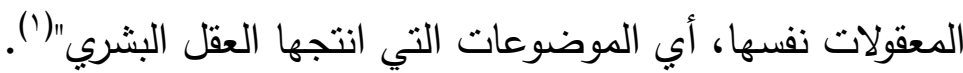
ومن خلال ذلك يتضح أن الفكر يراد به في الإجمال إعمال النظر والتأمل في مجموعة معارف للوصول إلى معرفة جديدة. ثالثاً: مفهوم الوسطية الفكرية:

مما سبق عرضة لبيان مفهوم الوسطية والفكر، يمكننا القول إن مفهوم الوسطية الفكرية هي: تحقيق التوازن والاعتدال في التواصل بين التقافات الإنسانية، ومنع الانغلاق والاكثقاء والاستغناء عن الآخر، والتفاعل معه من غير إفراط ولا تقريط، والبعد عن التعصب والتطرف الفكري، كل ذللك وفق الضوابط التي قررتها الشريعة الإسلامية. 


\section{المطلب الثاني}

\section{مفهوم الحوار الحضاري}

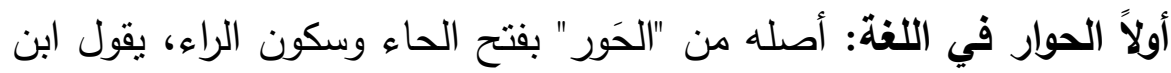
فارس:" الحاء والواو والراء ثلاثة أصول، أحدها: لون، والآخر : الرجوع، والثالث:

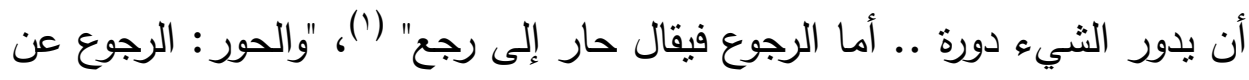

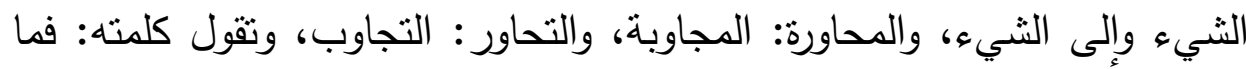

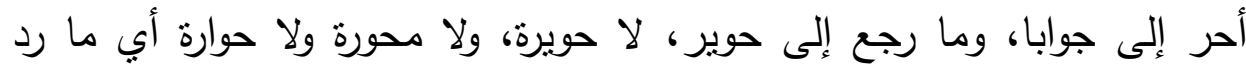

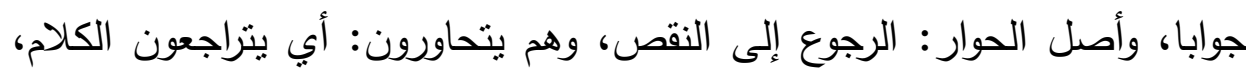
والمحاورة: مراجعة المنطق والكلام في المخاطية" (؟).

الحوار اصطلاحاً: تعددت تعريفات الحوار في الاصطلاح ولكنها في مجملها

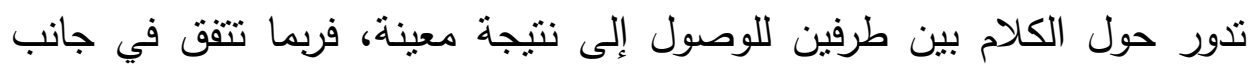

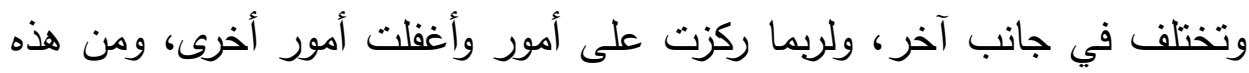
التعريفات: "الحوار هو الحديث بين شخصين، أو فريقين ينت فيه نداول الكيات الكلام

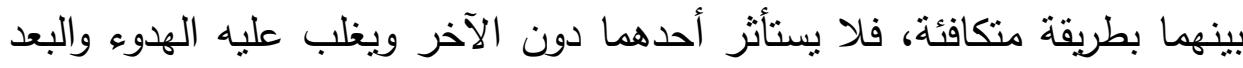
عن الخصومة والتعصب، وهو ضرب من الأدب الرفيع وأسلوب من أساليبه"((). ومنها: " أن يتتاول الحديث طرفان أو أكثر، عن طريق السؤال والجواب،

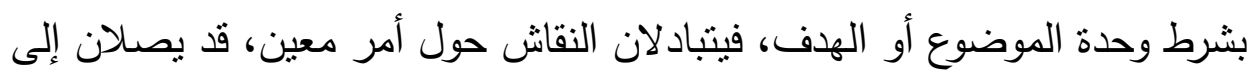
نتيجة وقد لا يقنع أحدهما الآخر ، لكن السامع يأخذ العبرة ويكون لنفسه موقفاً " (5).

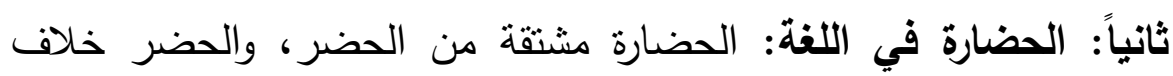
البدو، والحاضر خلاف البادي، ويقال فلان من أهل الحاضرة، وفلان من أهل البادية والحضارة بكسر الحاء الإقامة في الحضر، والحضر والحاضرة خلاف الفاف الحاف

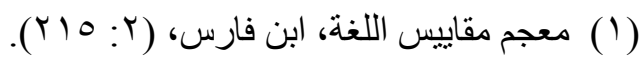

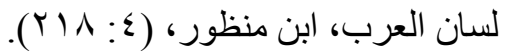

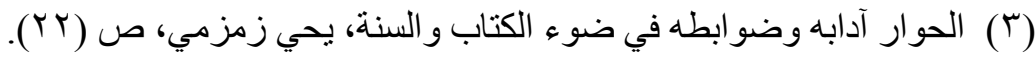

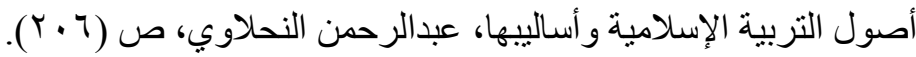

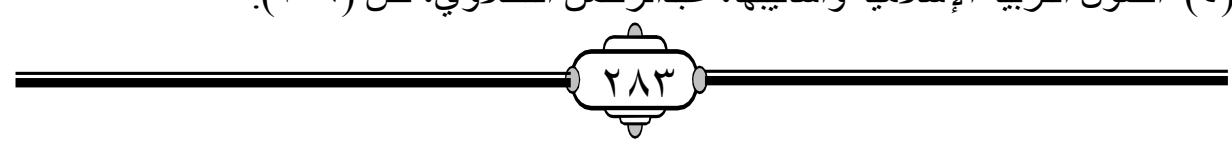




\section{الوسطية الفكرية وأثرها في الحوار الحضاري المعاصرل}

البادية، وهي المدن والقرى والريف، سميت بذللك لأن أهلها حضروا الأمصار، وسكنوا الديار التي يكون لهم بها قرار "(').

\section{الحضارة في الاصطلاح:}

تعددت تعريفات الحضارة وكان لابن خلدون رحمه الله السبق في وضع تصور وتعربف لمفهوم الحضارة فهي عنده ظاهرة اجتماعية تاريخية، وهي "التفنن في الترف واستجادة أحواله والكلف بالصنائع التي تؤنق من أسنافه وسائر فنونه من

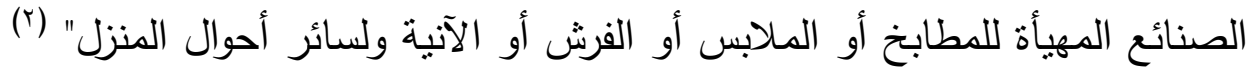
كما عرفت بأنها:" كل ما يخترعه الإنسان في سائر جوانب أنشطته العقلية والخلقية

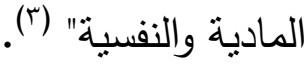

ولعل أبرز واشمل ما عرفت به الحضارة: " أنها الحصيلة الثاملة للمدنية

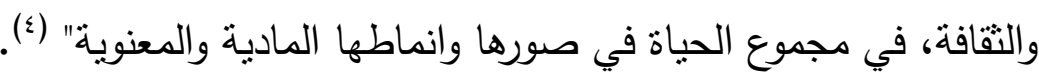
ثالثاً: مفهوم الحوار الحضاري:

بناء على ما تم التمهيد لله عن مفهوم الحوار والحضارة فقد عُرف الحوار الحضاري بعدة تعريفات لعل من أبرز هذه التعريفات أنه:" ذلك الحوار الذي يتم

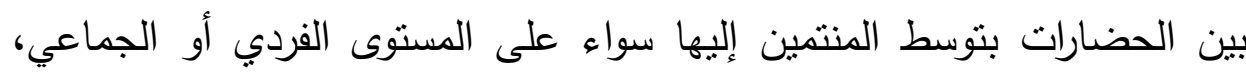

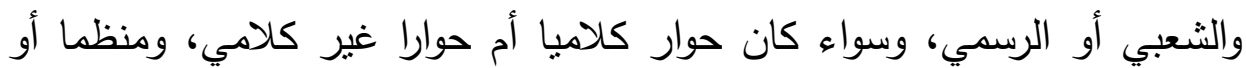

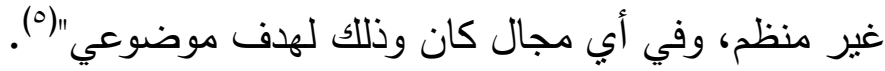

(الإسلام و الحضارة الغربية، محمد حسين، ص (1) (17 (1).

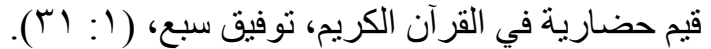

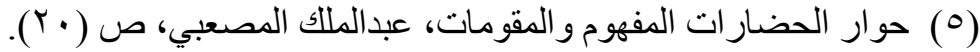


وقيل هو : " فهو التشاور والتفاعل الثقافي بين الثعوب، والقدرة على التكيف

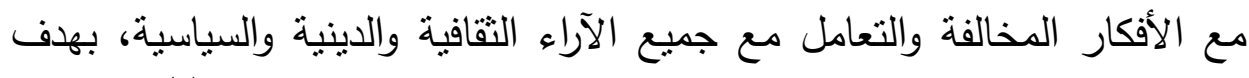
التعارف والتواصل والتفاعل والاحتكالك الحضاري، لتجنب الصراعات "((').

ومما سبق عرضه يضح لنا أن مفهوم الحوار الحضاري في مجمله يعود إلى مناقثة وتقريب وجهات النظر بين أطراف ثقافات الشعوب المختلفة، لأجل التعايش السلمي البعيد عن التعصب والتطرف في فلك معين.

( (1) القرآن الكريم طريقنا لتجاوز العجز الحضاري، وجدان فريق عناد، ص ( آY ).

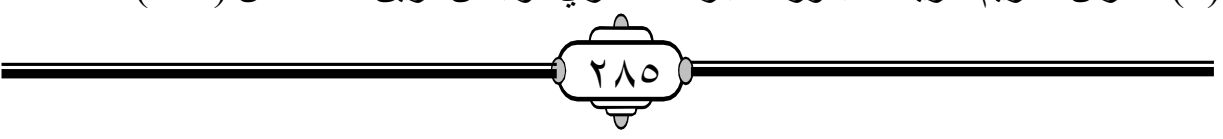




\section{المبحث الأول}

الوسطية الفكرية والحوار الحضاري

المطلب الأول

التأصيل الشرعي للوسطية الفكرية في الحوار الحضاري

أرست الثريعة الإسلامية قواعد الوسطية الفكرية في الحوار، وجعلته

أصل ثابت من أصولها في الدعوة إلى الله عز وجل والدين الحنيف، واهتم القرآن الكربم والسنة النبوية اهتماما بالغاً بالحوار الفكري المبني على الفي الوسطية والاعتدال

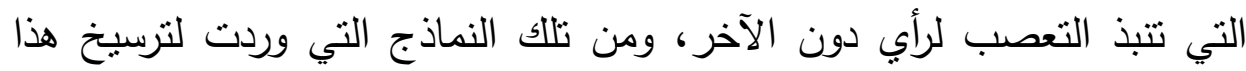
المعنى في القرآن الكريم:

ا: قوله تعالى:

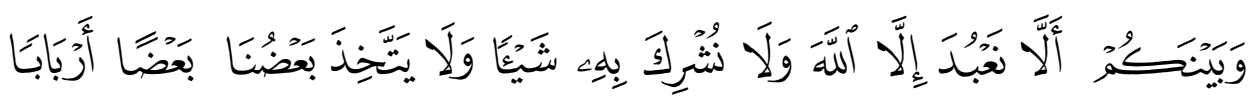

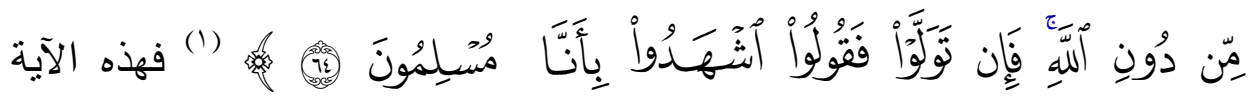
الكريمة تدعو إلى الحوار الهادئ المنصف المبني على الوسط والاعتدال والبعيد عن التعصب ونبذ الآخر، وهو ما يميز الحوار في الإسلام عن غيره، يقول

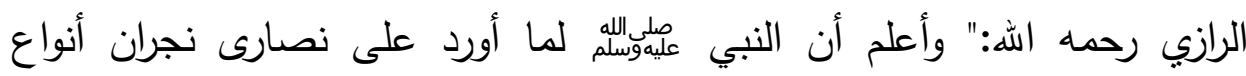
الدلائل وانقطعوا، ثم دعاهم إلى المباهلة فخافوا وما شرعوا فيها وقبلوا الصغار بأداء الجزية، وقد كان عليه السلام حريصا على إيمانهم، فكأنه تعالى قال: يا

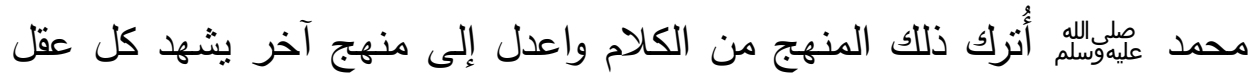
سليم وطبع مستقيم أنه كلام مبني على الإنصاف وترك الجدال، وقل يا أهل

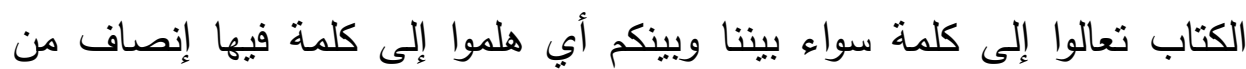
بعضنا لبعض، ولا ميل فيه لأحد على صاحبه، وهي ألا نعبد إلا الله ولا نشرك إك إك

(1) (1) سورة آل عمران، الآية (؟ ج). 


\section{به شبئا " (1) (1)}

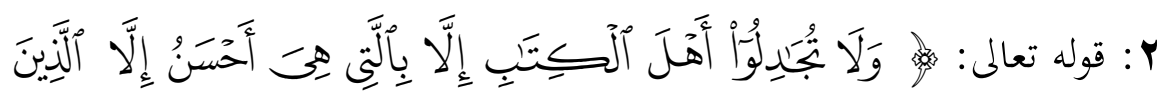

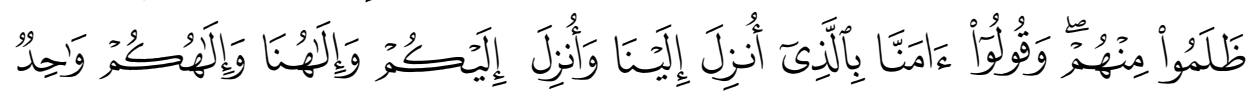

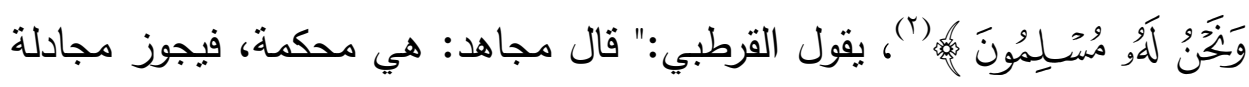
أهل الكتاب بالتي هي أحسن على معنى الدعاء لهم إلى الله عز وجل، والتتبيه على حججه وآياته، رجاء إجابته إلى الإيمان، لا على طريق الإغلاظ والمخاشنة" (").

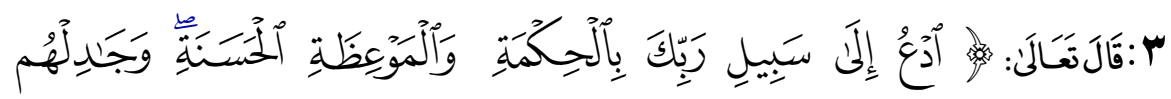

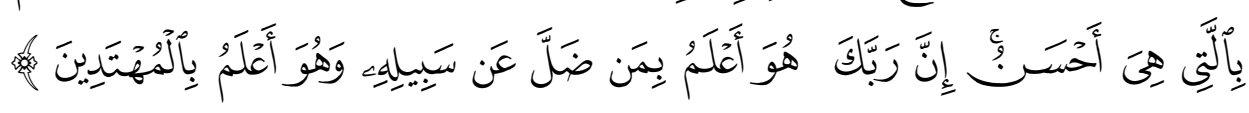
(๕)، يقول القرطبي رحمه الله:" هذه الآية نزلت بمكة في وقت الأمر بمهادنة قريش، وأمره أن يدعو إلى دين الله وشرعه بتلطف ولين دون مخاشنة وتعنيف، وهكذا ينبغي أن يوعظ المسلمون إلى يوم القيامة" (0)، ويقول ابن كثير رحمه الله: " أي ولي من احتاج منهم إلى مناظرة وجدال، فليكن بالوجه الحسن برفق ولين وحسن

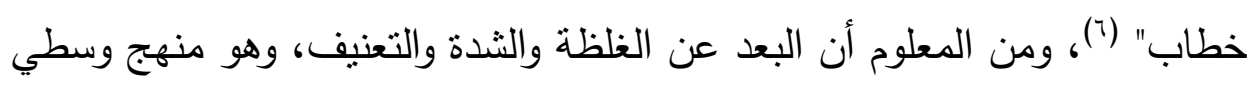
معتلال اتخذه النبي عليوسلم منهجا سار عليه هو ومن جاء بعده من صحابته رضوان الله عليهم أجمعين.

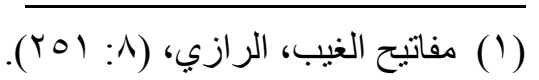

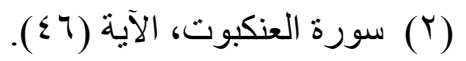

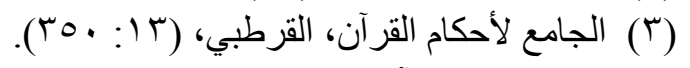

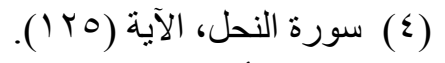

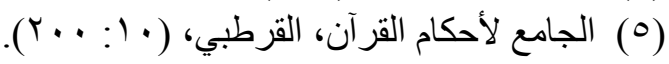

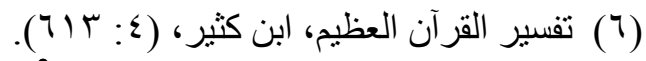

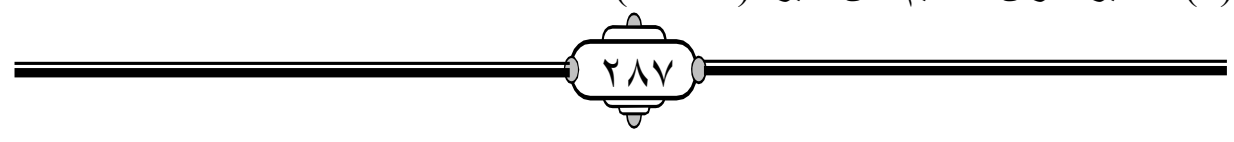




\section{الوسطية الفكرية وأثرها في الحوار الحضاري المعاصرل}

مما سبق يتضح أن القرآن الكريم اتخذ أسلوباً يبعد كل البعد عن الاستبداد، والعنف أو التعصب في الحوار، وأقر التوسط والاعتدال فيه، هذا التوسط والاعتدال الذي لا يعني أن يتتازل المرء عن ثوابت الدين، ولكن لكي يقرب وجهات النظر بحيث يستهوي فيه قلب الآخر لدين الله عز وجل.

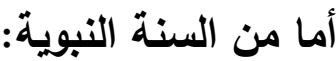

لقد كان النبي علملوسلهم أول المطبقين لهذه الدعوة القرآنية، والمجسِّدين لها على هلى

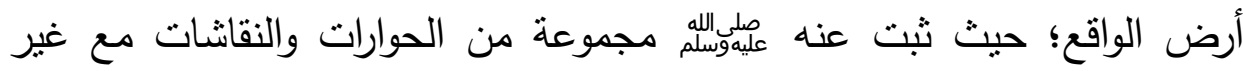
المسلمين، كما ثبت ذللك مع الصحابة رضوان الله عليهم، على نتوع تلك الحوارات

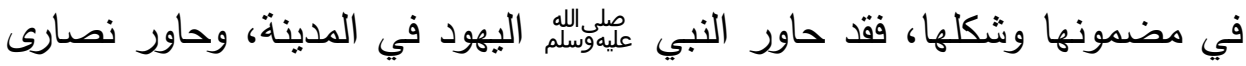
نجران، مع ما كان من حوار مع بعض أصحابه، ولكثرة تلك الحوارات في السنة النبوية سوف نعرض لبعض منها لتأصيل هذا الحوار المبني على الوسطية والاعتدال ومن هذه الحوارات:

\section{أولاً: حواره مع اليهود في المدينة:}

عندما هاجر النبي عليولسلم إلى المدينة أصبحت المدينة تضم مجموعتين عقديتين المسلمين واليهود إلى جانب بعض المشركين، أراد النبي علئلسلم أن بنظم الحياة داخل المدينة فعقد معاهدة المدينة التي تتظم الحياة فيها، فسرعان ما أراد اليهود نقض هذه المعاهدة عندما رأوا مصلحة المسلمين فيها، فأدرك الرسول عليهولسلم أن اليهود بريدون بعث الضغائن ونشر الحقد والجدل العقيم بين المسلمين كما أدرك أنهم يستخدمون لبلوغ مآربهم رصيدهم المعرفي المتمثل في التوراة التي بعني

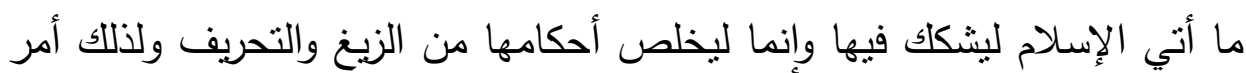

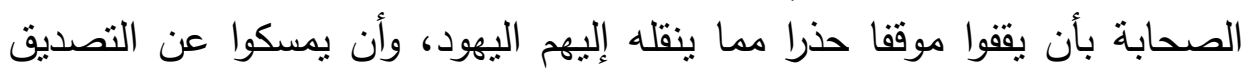
والتكذيب، فقد عقد البخاري رحمه الله بابا في كتاب الاعتصام بالكتاب والسنة عنون له: باب قول النبي عليولسلم: لا تسألوا أهل الكتاب عن شيء، وخرج فيه حديث أبي هريرة رضي الله عنه قال:" كان أهل الكتاب يقرؤون التوراة بالعبرية

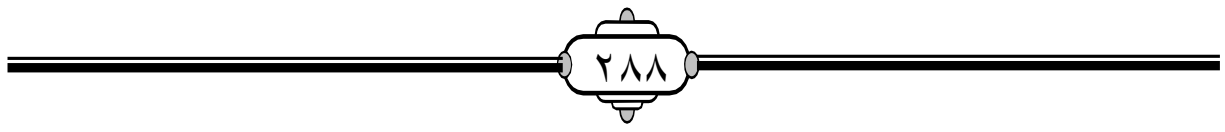




\section{الوسطية الفكرية وأثرها في الحوار الحضاري المعاصرح}

ويفسرونها بالعربية لأهل الإسلام، فقال رسول الله عليولسلم: لا لا تصدقوا أهل

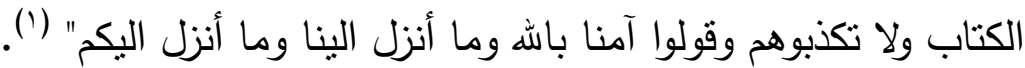

لقد تتوعت حوارات النبي عليهوسلمه مع اليهود، فكانت في جوانب عدة منها ما

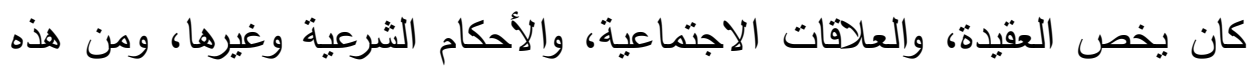
الحوارات ما كان بينه وبين حبراً من أحبار اليهود سأله عن بعض الأموانها والهور الغيبية

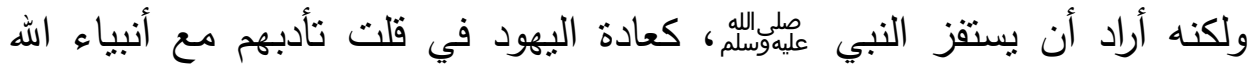

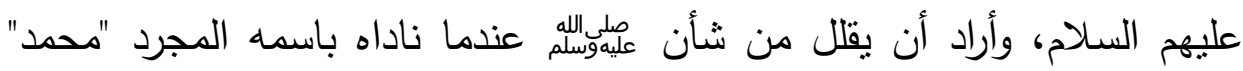
بدلا من رسول الله فعند مسلم رحمه الله أن ثثبان مولى رسول الله علئوسلمله قال:"

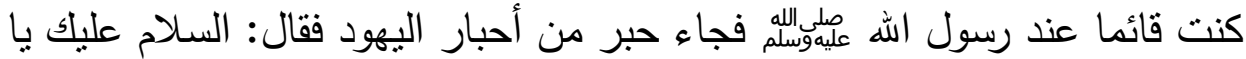
محمد فدفعته دفعة كاد يصرع منها فقال: لم تدفعني فقلت: ألا تقول يا رسول الله،

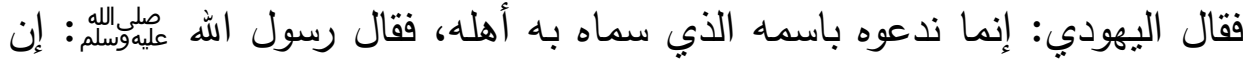
اسمي محمد الذي سماني به أهلي، فقال اليهودي: جئت أسألك، فقال له رسول الله

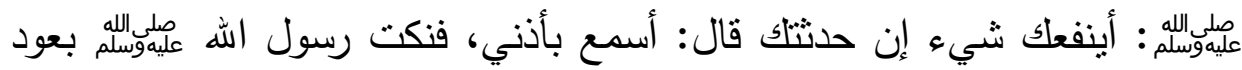

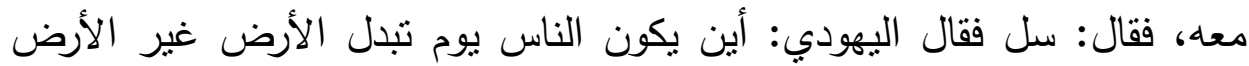

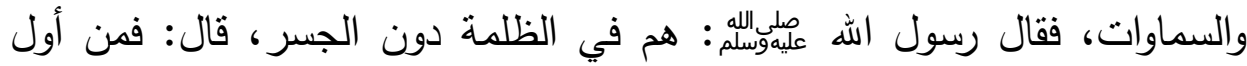
الناس إجازة قال: فقراء المهاجرين، قال اليهودي: فما تحفتهح حين يدخلون الجنة، قال: زيادة كبد النون، قال: فما غذاؤهم على إثرها، قال: ينحر لهم ثور الجنة الذي كان يأكل من أطرافها، قال: فما شرابهر عليه، قال: من عين فيها تسمى سلسبيلا،

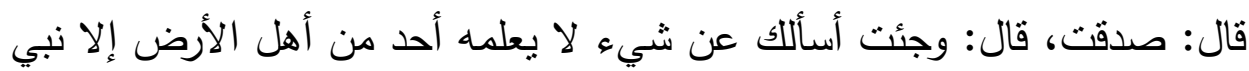

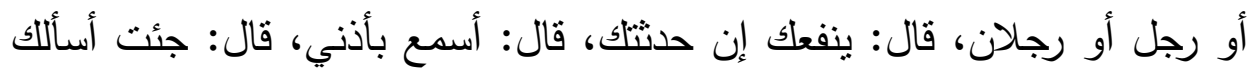

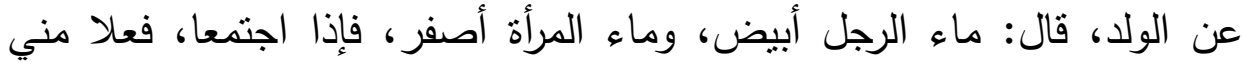
الرجل مني المرأة، أذكرا بإذن الله، وإذا علا مني المرأة مني الرجل، آنثا بإذن الله، قال اليهودي: لقد صدقت، وإنك لنبي، ثم انصرف فذهب، فقال رسول الله عليموسلمه :

$$
\text { (1) صحيح البخاري، كتاب الاعتصام، (9:9 (1))، ورقمه (r (1) (YT). }
$$




\section{الوسطية الفكرية وأثرها في الحوار الحضاري المعاصرل}

لقد سألني هذا عن الذي سألني عنه، وما لي علم بثيء منه، حتى أناني الله

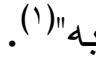

والناظر في هذا الحوار الذي دار بين رسول الله عليمولالله وهذا الحبر من اليهود، يجد الإنصاف منه عليهليلهم مع علم الرسول عليهوليلم باليهود الذين يعادونه ويتربصون به الدوائر، وما بهم من مكر ونقضهم للعهود والمواثيق وكتمهم للحق

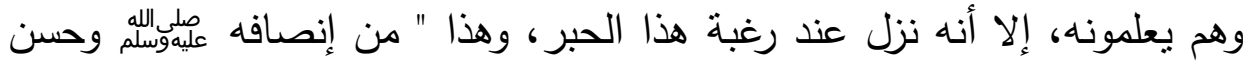

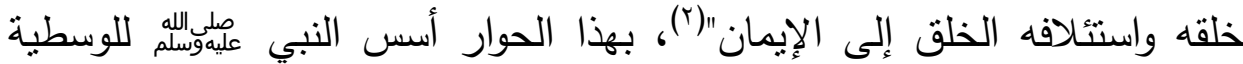

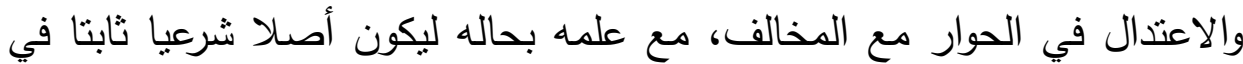
الدعوة إلى الله.

\section{ثانياً: حواره علملوسلالهم مع النصارى:}

كان الاحتكاك المباشر والغالب من أهل الكتاب بالنبي عليولسلمه من اليهود؛

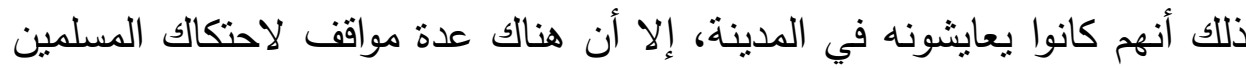
بالنصارى، وكان أولها لقاء المسلمين المهاجرين إلى الحبشة بنصارى الحبشة،

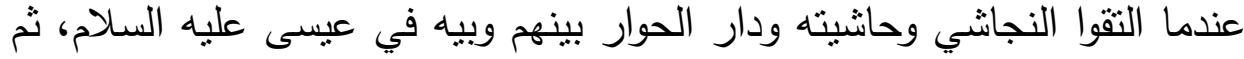

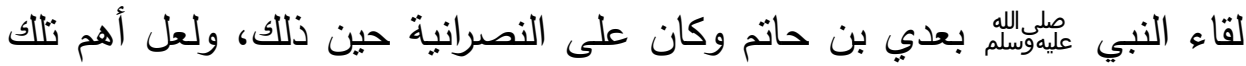
الحوارات واللقاءات ما كان بين النبي عليهولسلم وبين وفد نصارى نجاءله نهان في عام الوفود في المدينة في السنة التاسعة من الهجرة، أرسل نصارى نجران وفد للمدينة

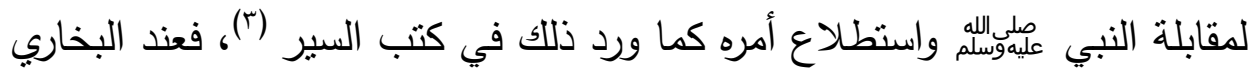
رحمه الله عن حذيفة، قال:" جاء العاقب والسيد، صاحبا نجران، إلى رسول الله عليولسلم يريدان أن يلاعناه، قال: فقال أحدهما لصاحبه: لا تفعل، فواله لئن كان نباء نبيا فلاعنا لا نفلح نحن، ولا عقبنا من بعدنا، قالا: إنا نعطيك ما سألتنا، وابعث معنا

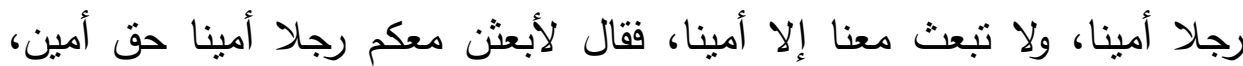

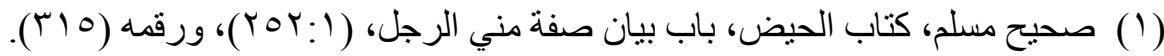

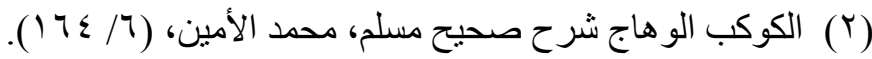

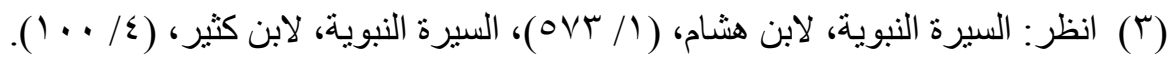
$=\overbrace{\text { rq. }}^{\text {rq. }}=$ 


\section{الوسطية الفكرية وأثرها في الحوار الحضاري المعاصرل}

فاستشرف له أصحاب رسول الله عليولسلم فقال: قم يا أبا عبيدة بن الجراح فلما قام، قال رسول الله عليموسلم: : هذا أمين هذه الأمة "(')

يقول ابن هثام في الحوار الذي دار بين النبي عليولسللم وسادة الوفد: "فلما

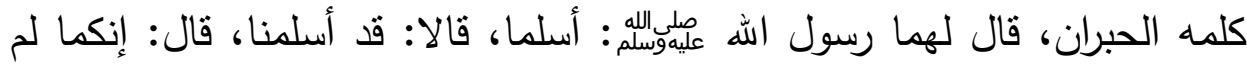
تسلما فأسلما قالا: بلى، قد أسلمنا قبلك: قال: كذبتما، يمنعكما من الإسلام

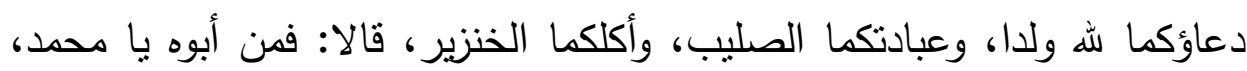
فصمت عنهما رسول الله عليولسلم فلم يجبهما، فأنزل الله تعالى في ذلك من قولهم، واختلاف أمرهم كله، صدر سورة آل عمران إلى بضع وثمانين آية منها" (r). كما علق الرازي رحمه الله فقال:" واعلم أن النبي عليقولسلمه لما أورد على نصارى نجران أنواع الدلائل وانقطعوا، ثم دعاهم إلى المباهلة فخافوا وما شرعوا فيها وقبلوا الصغار بأداء الجزية، وقد كان عليه السلام حريصا على إيمانهم، فكأنه تعالى قال: يا محمد عليهولسلم اترك ذلك المنهج من الكلام وعدل إلى منهج آخر يثهـ كل عقل سليم وطبع مستقيم أنه كلام مبني على الإنصاف ونزك الجدال، وقل يا أهل الكتاب تعالوا إلى كلمة سواء بيننا وبينكم أي هلموا إلى كلمة فيها إنصاف من

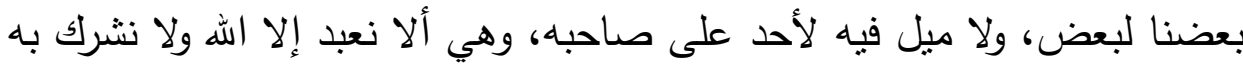

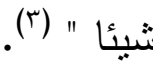

والناظر في حواره علئوسلمه مع وفد نصارى نجران يجد التوسط والاعتدال منه

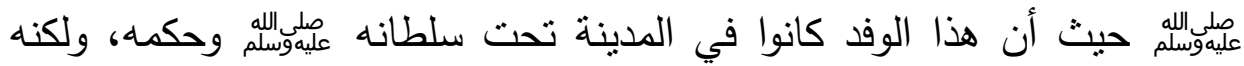
أكرم وفادتهم وأنزلهم خير منزل وبالغ في إكرامهم ولم يمسهم أحد بأذى، والتزامه

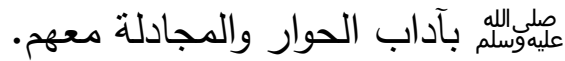

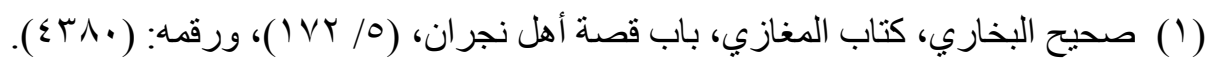

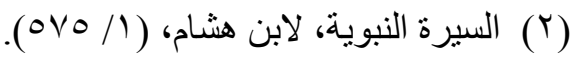

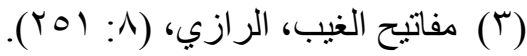


ومما سبق عرضه في حواراته عليموللمه مع غير المسلمين إضافة لما كان بينه

وبين أصحابه وهي كثيرة ومتنوعة، يتضح أن الثريعة الإسلامية أصلت لهذا

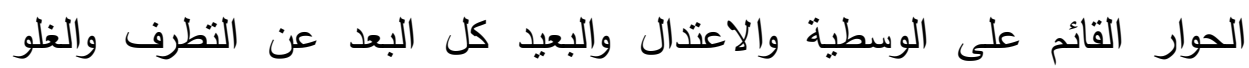
والاستبداد والاستئنار بالرأي دون الآخر، بل جعلت لهذا الحوار آداب وقواعد مع التع احترام المحاور ورأيه.

المطلب الثاني

أصول وأسس الحوار الحضاري

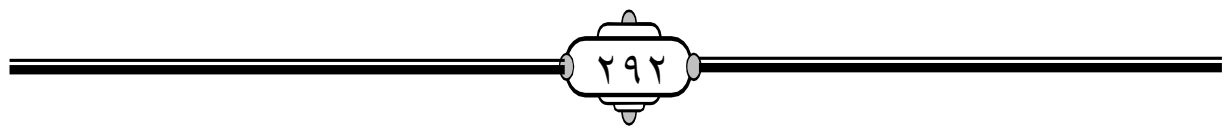


أصول الحوار هي عبارة عن القواعد الرئيسية الثابنة التي تضبط عملية الحوار، والتي هي في الواقع تساعد وتسهم في نجاح هذ الحوار، وقد جعل بعض الدض

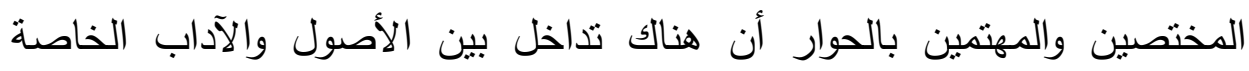

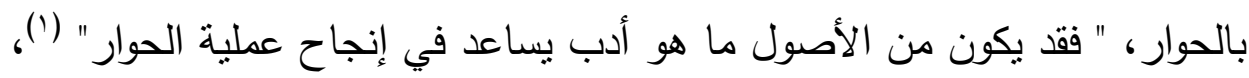
ولعل من أبرز هذه الأصول والأسس ما يلي: لأئ هول

أولاً: تحديد الهدف، ويدخل ضمن تحديد الهدف أيضا تحديد القضية التي يدور حولها الحوار، وتحديد موضوع الحوار ونقطة الاختلاف، فقد يختلف المتحاوران في

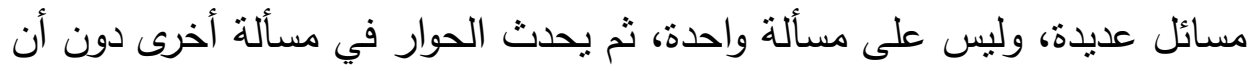
يتفق على المسألة الأولى، فيتشعب الحوار وبطول بعيدا عن موضوع المحاورة، يقول الربيع بن سليمان رحمه اله: "كان الثافعي إذا ناظره إنسان في مسألة فعدا إلى غيرها، يقول: نفرغ من هذه المسألة ثم نصير إلى ما تربد" (؟). ثانياً: التجرد في طلب الحق، والحذر من التعصب والهوى، وهذا الأصل هو ما أكد عليه المفكر الفرنسي جارودي في كتابه حوار الحضارات حيث اشترط ليكون الحوار ناجحا شروطا عدة منها، "التخلص من الأفكار السابقة التي ترى أفضلية الحضارة الغربية على غيرها من الحضارات، وأن تحتل الحضارات غير الغربية في الدراسات مكانة منساوية في الأهمية، على الأقل لمكانة الثقافة الغربية، الاعتراف

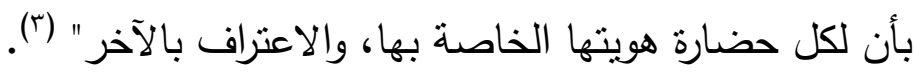
من ذلك ما يُروي عن الإمام الثافعي رحمه الله أنه قال:" ما ناظرت أحدا قط

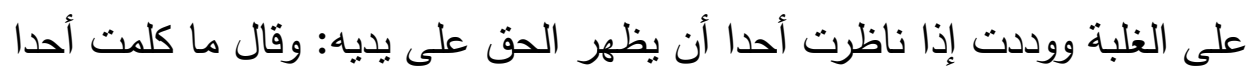
قط إلا وددث أن يوفق ويسدد ويعان ويكون عليه رعاية من الله وحفظ" (؛)،

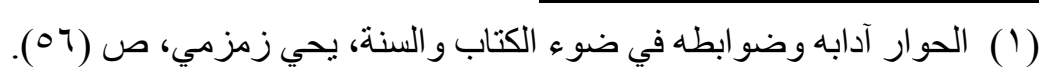

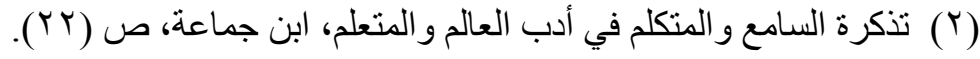

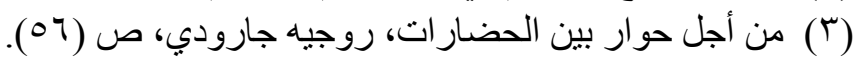

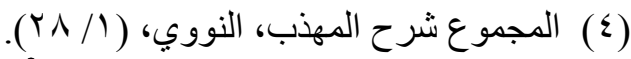

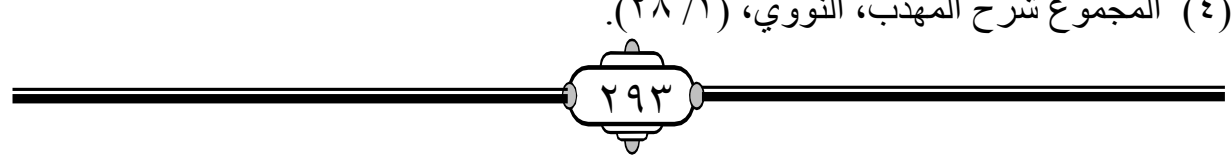




\section{الوسطية الفكرية وأثرها في الحوار الحضاري المعاصر}

والمقصود من ذلك أن يكون الحوار بريئا من التعصب خالصا منه لطلب الحق، خاليا من العنف والانفعال، بعيدا عما يفسد القلوب ويهيج النفوس.

ثالثاً: الاتفاق على أصل يرجع إليه، والأصول المرجعية عند المسلمين هي الكتاب والسنة، وما كان عليه السلف، وقد أمر الله بالرد إليه وإلى رسوله في عدة

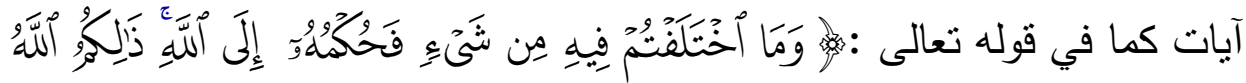

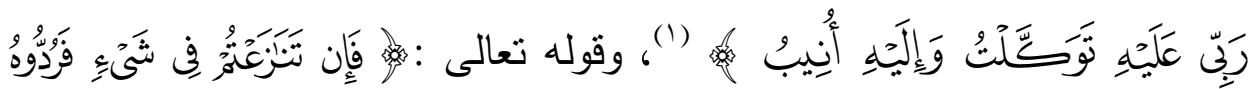

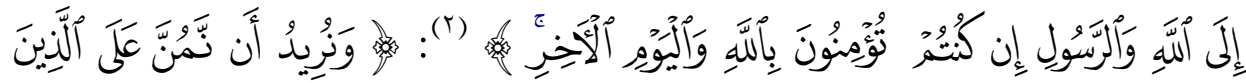

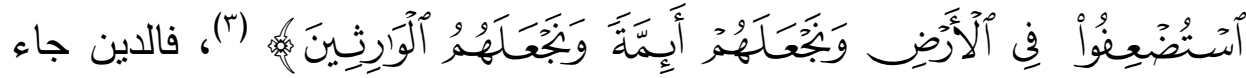
لتحقيق العدل وردع الظلم والضيم، ولن تجد البشرية اليوم دينا يحقق السلام ويوقف الحروب والتراعات التي أنهكت بني الإنسان غير الدين الإسلامي، فاله هو السلام

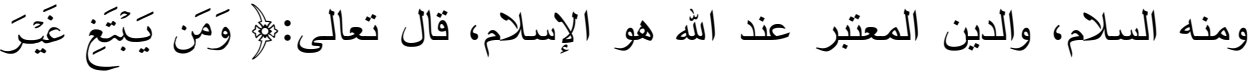

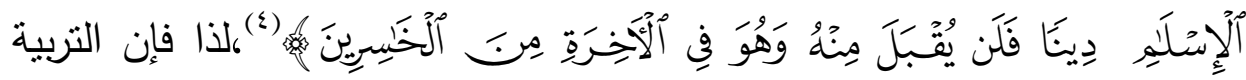
على القيم بمختلف أنواعها منذ الصغر أصل من أصول الحوار بين الناس كافة وخاصة ما يتعلق بنشر ثقافة الاحترام المتبادل والتسامح، والتسامح وفق المنظور الإسلامي، فضيلة أخلاقية، وضرورة مجتمعية، وسبيل الضبط الاختلافات وإدارتها، فالتسامح سلوك وموقف ليس دليل ضعف، بل هو من مقتضيات القيم ومتطلبات الالتزام بالمبادئ، فالغلظة والثدة والعنف في العلاقات الاجتماعية والإنسانية، هي المناقضة للقيم، وهي المضادة لطبيعة منطلبات الحياة وهي دليل ضعف وخواء،"ولذا فإن التسامح الذي يقود التعايش يؤدي إلى الاستقرار

$$
\text { سورة سورة الثورى، الآية (•) (1). }
$$


الاجتماعي وتطوير أواصر وأسباب التعاون بين مختلف شرائح المجتمع، هو من صميم القيم الإسلامية النبيلة" (')، وكل إنسان خالف ذللك، ومارس الغلظة والثدة في علاقاته الإنسانية والاجتماعية لدواع مختلفة، هو الذي يحتاج إلى مبررات عديدة ومتتوعة لتبرير موقفه الغليظ، فالأصل في العلاقات الاجتماعية والإنسانية، أن تكون علاقات قائمة على المحبة والمودة والتالف، فسر ابن كثير رحمه الهه قول

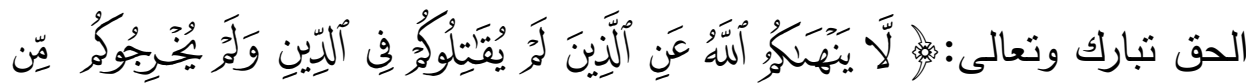

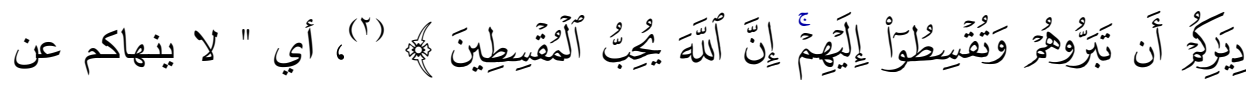
الإحسان إلى الكفرة الذين لا يقاتلونكم في الدين، كالنساء والضعفة منهم أن تحسنوا

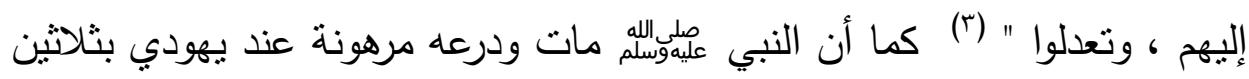
صاعا من شعير أخذها طعاما لأهله، فعن عائشة رضي الله عنها، قالت: "توفي

رسول الله عليولسلم ودرعه مرهونة عند يهودي، بثلاثثين صاعا من شعير" (ع). فيتوجب الاهتمام والحرص على منل هذه القيم الحضارية في الحوار ليعلوا

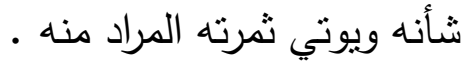

المطلب الثالث

أهمية الوسطية الفكرية في الحوار الحضاري

$$
\begin{aligned}
& \text { ( الحوار بين أنباع المذاهب، عبدالمحسن السميح، ص (No1) (1). } \\
& \text { سورة الممتحنة، الآية (^). (1). } \\
& \text { تفسير القر آن العظيم، ابن كثير، (^) (^) • 9). }
\end{aligned}
$$

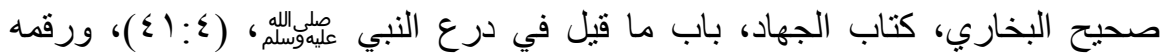


تذعو الحاجة إلى الحوار وضرورة استعماله، فهو طريقاً يسعى من خلاله المسلم إلى نشر دعوته، بل أنه يكاد أن يكون من أهم الطرق والوسائل التي يسلكها المسلم لنشر دعوته الصحيحة، وبه يحق الحق ويبطل الباطل، فهو الوسيلة المتلى لبيان الحق وإيصاله، وهو السالح الذي يُرد به على الثبهات ويبطلها ويبين الحق فيها.

ولذلك كلما كان الداعية متقناً لهذا الفن متمكنا منه يعرف آدابه وضوابطه وأساليبه، بقدر ذللك يكون نجاحه فيه، وليكون هذا الحوار بعيدا عن التعصب والمجافاة، مؤديا لما يرجى منه، لا بد أن يكون قائما على التوسط في الفكر متجردا من التعصب لرأي، ولعل أهمية الوسطية الفكرية في الحوار الحضاري المعاصر يمكن أن تبرز من خلال النقاط التالية:

أولا: كثرة استعماله في القرآن الكريم، والسنة النبوية المطهرة على صاحبها أفضل الصلاة والسلام، فقد حكاه الله عز وجل وقصه في محكم التنزيل للأنبياء عليهم السلام مع أقوامهم، ذلك في دعوتهم للحق والتوحيد ونبذ الثرك وعبادة غير الله عز وجل، فلقد وقعت هذه الحوارات التي بُنيت على التوسط والاعتدال من الأنبياء كلهم مع أقوامهم، ومن هذه النماذج التي قصها علينا القرآن الكريم وهي كثيرة، ما وقع بين نبي الله لوط عليه السلام مع قومه، ذلك عندما قدمت إليه الملائكة لتخبره بوقوع عذاب الله على قومه، فعندما أخبرت أمرأة لوط القوم بقدوم الأضياف إلى لوط عليه السلام، جاء القوم إليه بطلبون منه أن يخلو بينهم وبين أضيافه، فحدث من الحوار بين لوط وقومه ما قد قصه القرآن علينا قال تعالى :

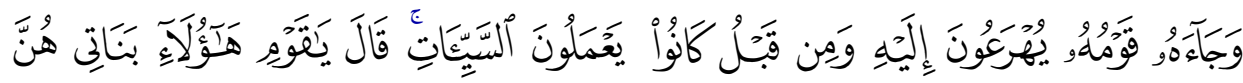

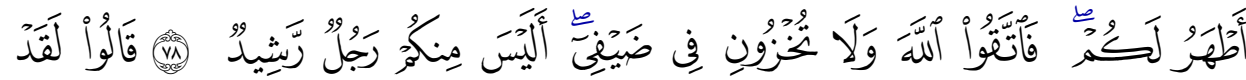

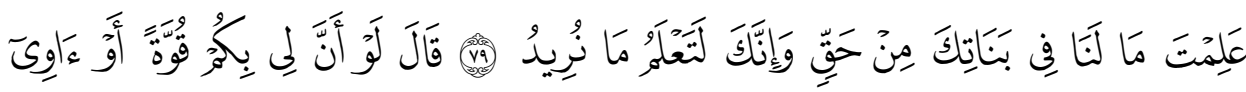

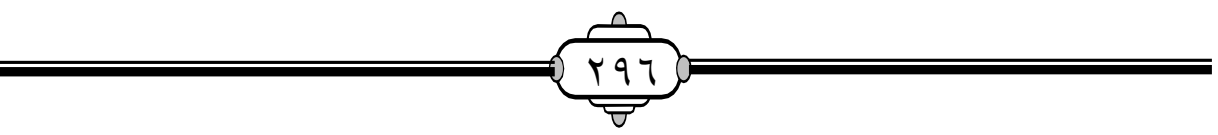




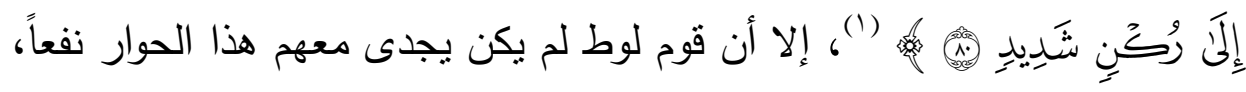
ولم يكن يؤتي ثماره؛ لاستكبارهم وبطرهم للحق، ولوقع عذاب اله عليهم، مع أنه

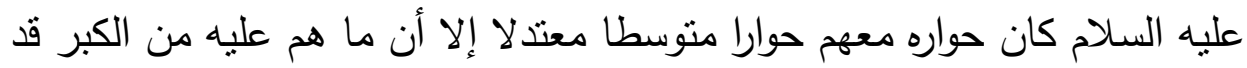

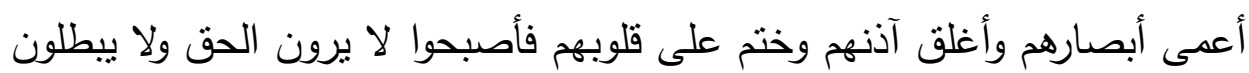

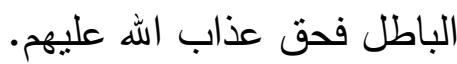

والأمتلة في السنة النبوية على صحبها أفضل الصلاة والسلام كثيرة فكل دعوته عليلوسللم كانت قائمة على الجانب الحواري الذي يقوم على التنوسط والاعتدال، فحاور عليلونلسله قومه في بداية بعتثه ودعوته في مكة، وعندما هاجر إلى المدينة وجد اليهود وكانت بينهم وبينه عدة حوارات، وحاور النصارى من أهل نجران

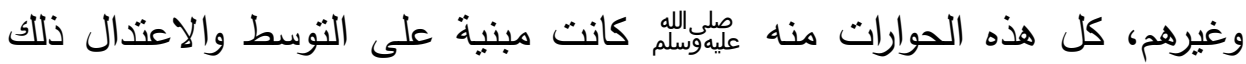

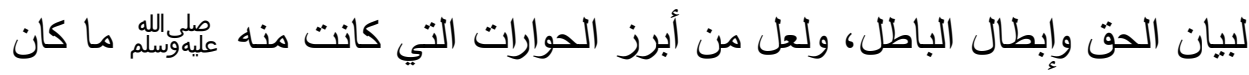
بينه وبين اليهود؛ ذلك لأن اليهود أهل كتاب وأصحاب علم، عندما قدم المدينة،

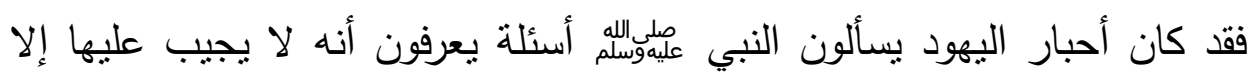

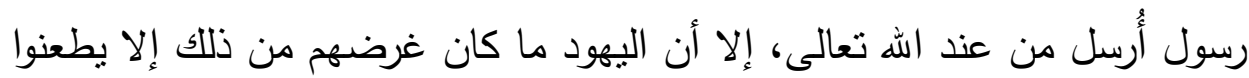

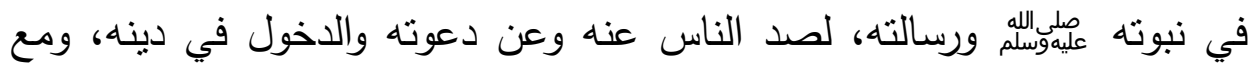

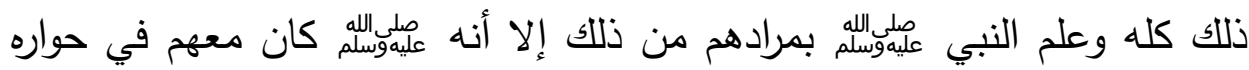
منصفا عادلا بعيدا عن التعصب معتدلا، فكل ما سألوه سؤلا جاء الوحي من إن الته السماء بالرد فأخزاهم الله وأذلهم.

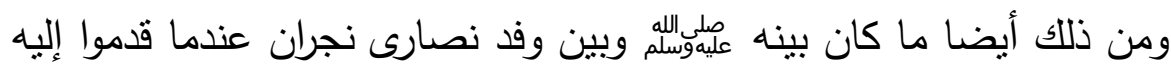

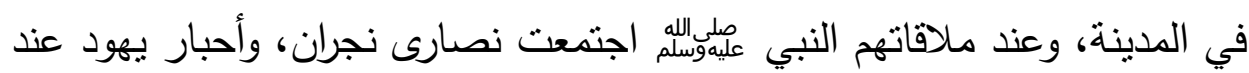

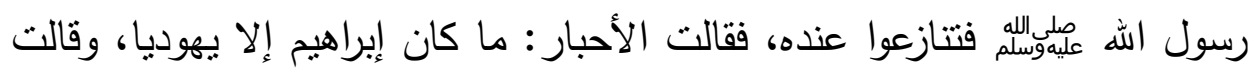




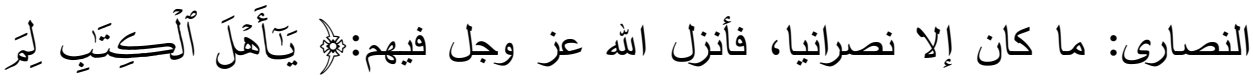

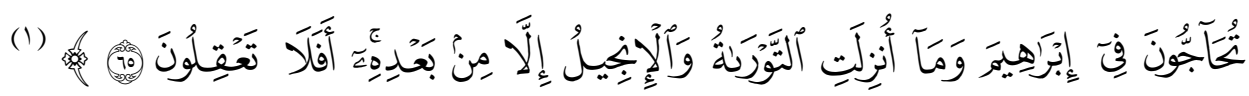
فقال رجل من الأحبار : أتربد منا يا محمد أن نعبدك كما تعبد النصارى عيسى ابن مريم، وقال رجل من نصارى نجران: أوذلك تريد يا محمد وإليه تدعونا، فقال رسول الله عليلوسلله: معاذ الله أن أعبد غير الله، أو آمر بعبادة غيره، ما بذلك بعثي ولا

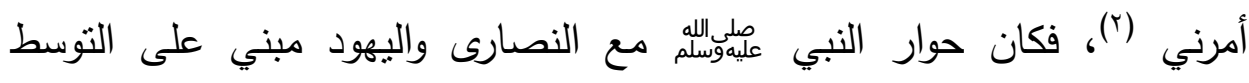
والاعتدال البعيد عن التعصب ذلك لبيان الحق وإبطال الباطل.

والناظر في هذه الكثرة في استعماله كما بينا سابقاً يتبين له الأثر الإيجابي الذي هو في الواقع أكبر دليل يبين لنا أهمية الوسطية الفكرية في الحوار ودوره الإيجابي فيها، فكم من كافر عندما رأى هذا المنهج وهذا السلوك دخل في الإسلام، وكم من عاص تاب، وكم من مبتلّع رجع عن بدعته.

\section{المبحث الثاني}

مظاهر الوسطية الفكرية في الحوار الحضاري وآثارها

المطلب الأول

ضوابط الوسطية الفكرية في الحوار الحضاري

(1) (10) سورة آل عمر ان، الآية (10).

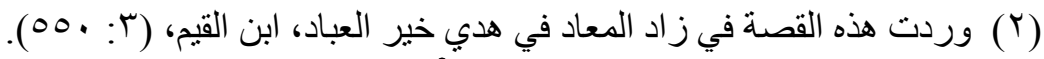


تتعدد وتتتوع مجالات الوسطية الفكرية في الإسلام، فهي داخلة في جميع

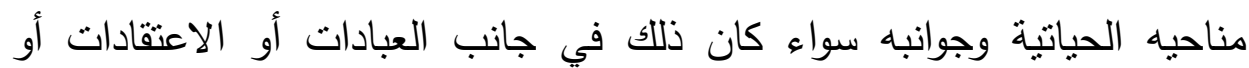

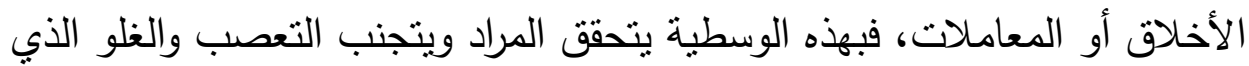
حذر منه الله ورسوله عليلوسلمه ، ومن هذه المجالات الحوار؛ فالوسطية في الحوار من أهم ما ينبغي أن تراعى ويهنم بها لأهميتها في الاعوة إلى الله، ولا شك أن هذه اله الوسطية مضبوطة بضوابط الثرع التي نراعي القواعد الكلية، والمقاصد الثرعية، ولعل من أهم هذه الضوابط ما يلي:

أولاً: أن تكون موافقة لما جاء في الكتاب العزيز والسنة النبوية المطهرة، فتعتمد على النصوص والأدلة الثرعية، فيكون بذلك لزاما الرجوع فيها إلى الثارع الحكيم فيما ورد فيه نص وإلا بالقياس الصحيح على مثيلها ونضيرها من الوقائع،

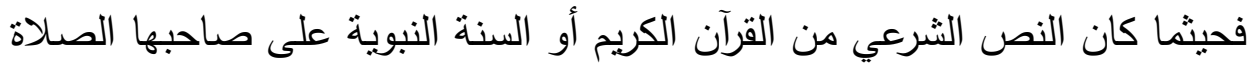
والسلام كان ذللك الوسط والاعتدال وما خالفهما كان ذللك الغلو والجفاء والتعدي، ومما لم يكن فيه نص فالوسط والاعتدال فيه ما كان موافقا للفطرة والحكمة والعدل

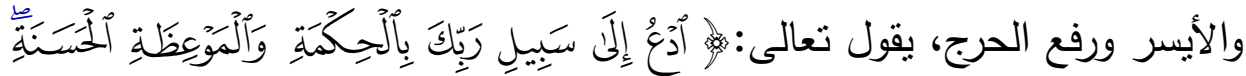

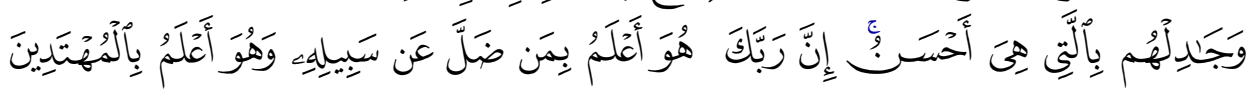

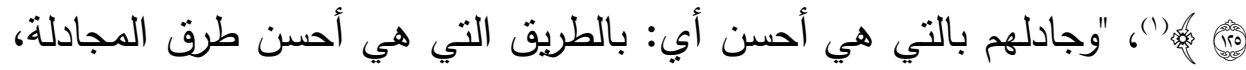
وإنما أمر سبحانه بالمجادلة الحسنة لكون الداعي محقا وغرضه اله صحيحا، وكان بان

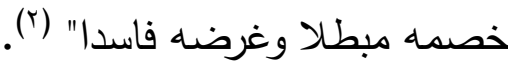

وهذه الدعوة التي تكون بالحكمة والنظر في أحوال المدعوين والمحاورين، أو الموعظة الحسنة التي تككن مبنية على الرفق واللين، التي هي بعيدة كل البعد عن الفضاضة والتكبير والزجر والوعيد، إنما هي بلا شك ناتج من نواتج التوسط هيط لئه

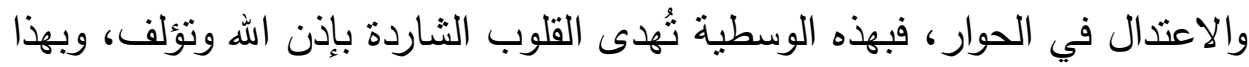
الجدل الذي لا يكون فيه تحامل على المخالفين يقع الاطمئنان إلى المحاور ، الذي لئي 
يشعر به طرف الحوار الآخر ويعرف أنه إنما كان الغرض من هذا الحوار هو

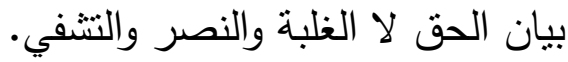

ثانياً: ألا تخالف منهج الصحابة رضوان الله عليهم والسلف الصالح، فالصحابة رضوان الهه عليهم هم خير الناس فهما لنصوص الكتاب والسنة النبوية المطهرة، وهم أعلم الخلق بأحكام الشربعة؛ ذلك لقرب عهدهم بالوحي ولأنهم شاهدوا

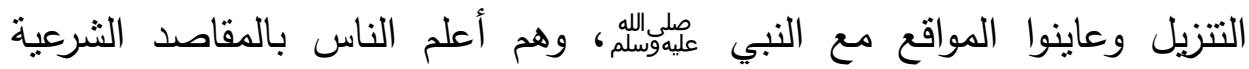
لمشاهدتهم هذه الوقائع في حينها وأخذهم من النبي عليهولسلم في حينه. فإن اتفقوا على شيء قلا شك ولا ريب أن الوسطية والاعتدال فيما اتفقوا عليه، وما خالفهم في ذلك فهو الغلو والجفاء والتطرف، لذلك كان من ضوابط الوسطية في الحوار أن يتوافق مع ما كان عليه الصحابة رضوان الله عليهم والسلف الصالح في القواعد الثرعية وما خالف ذللك يعد ميلا عنها. ولأن السلف هم أثد الناس اتباعاً لسنة النبي علموسللم وأحفظهم لها، وأبعد الناس عن الهوى فيها وقد زكاهم النبي عليهولللم ووصفهم بالخيرية فقال عليهولسلمه :

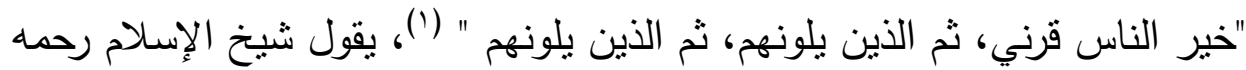

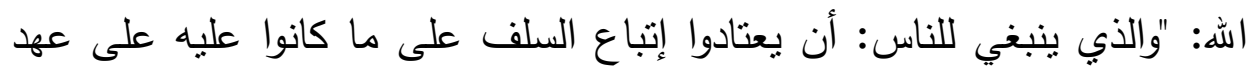

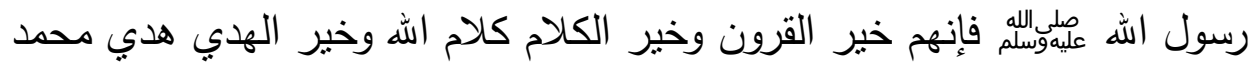
عليولسلم فلا يعدل أحد عن هدي خير الورى وهدي خير القرون إلى ما هو دونه"(r)،

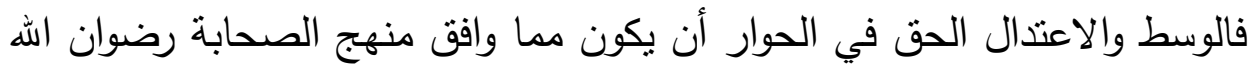
عليهم والسلف الصالح عليهم رحمة الله. ثالثاً: أن تراعي هذه الوسطية القواعد الكلية، والمقاصد الثرعية، وألا تخالف

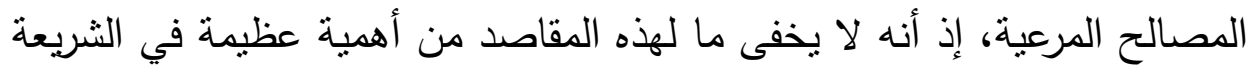

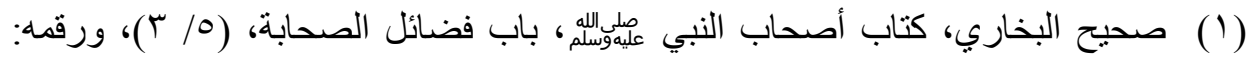
(Y) مجموع الفتاوى، ابن تيمية، (Y / (Y (Y).

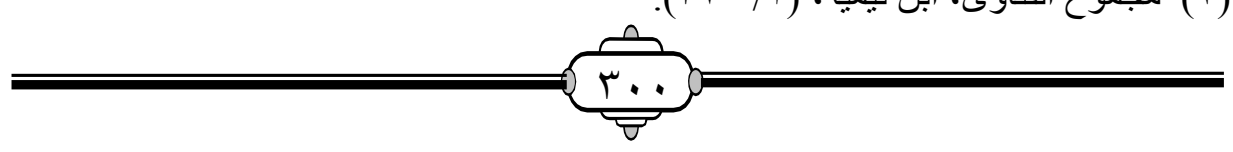




\section{الوسطية الفكرية وأثرها في الحوار الحضاري المعاصرل}

الإسلامية لما فيها من تحقيق المصالح ودفع المضار، فالوسطية الفكرية في الحوار الحضاري راعت هذه المقاصد والمصالح إذ هي من أهم ضوابطها. رابعاً: أن يتولى بيانها أهل العلم المعتبرون (')، فالعلماء هم ورثة الأنبياء، وهم من أخذوا هذا العلم من منبعه الصافي وتوارثوه جيل بعد جيل من النبي عليهولسلم

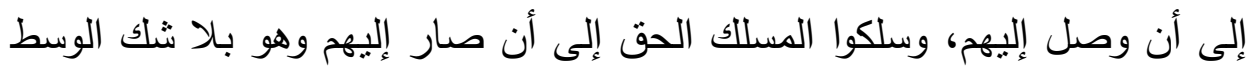
والاعتدال، لللك كان من أهم ضوابط الوسطية في الحوار أن يتولى توضيحها

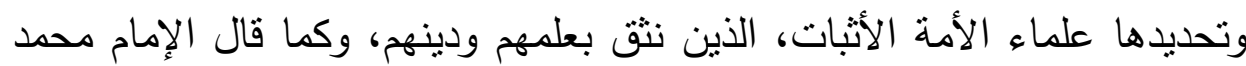
بن سيرين رحمه الهه: "إن هذا العلم دين، فانظروا عمن تأخذون دينكم" (؟) ولأن

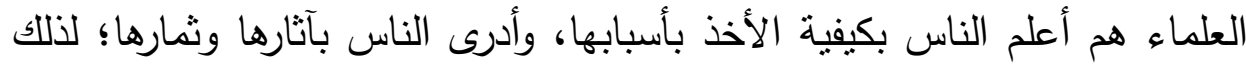

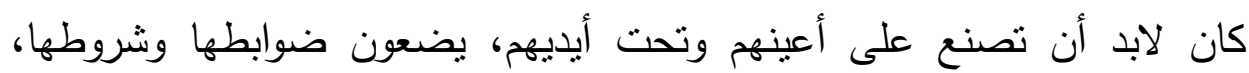
ويزنونها بميزان الكتاب والسنة بما يوافق فهم سلف الفان الأمة.

هذه أهم ضوابط الوسطية في الحوار والتي يجب أن تراعى ويتوقف عندها.

\section{المطلب الثاني}

\section{مظاهر الوسطية الفكرية في الحوار الحضاري.}

الوسطية في الحوار الحضاري حاجة إنسانية؛ لأنها تؤدي إلى الانفتاح والتواصل مع التقافات الإنسانية، فالاعتدال والوسطية يمنعان من الانعزال والانكفاء

$$
\begin{aligned}
& \text { (1) بلوغ الآمال في تحقيق الوسطية والاعتدال، عبدالرحمن السديس، ص (1) (1). }
\end{aligned}
$$

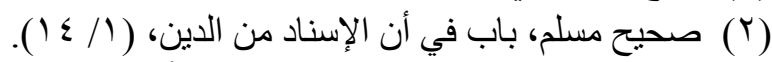




\section{الوسطية الفكرية وأثرها في الحوار الحضاري المعاصرح}

والاستغناء عن الآخر، ويؤديان إلى التفاعل معه، والانفتاح على التقافات والتواصل الإنساني، ولا شك أن أصل هذا الانتفاع هو كتابه وسنة نبيه عليوسلمله، حيث جاء هذا المنهج الرباني العالمي يأمرنا بعمارة الأرض وبناء الحياة وتطويرها، والمتأمِل للسيرة النبوية وتاريخ السلف الصالح من هذه الأمة يجد أن الأمة الإسلامية تعاملت مع غيرها من الأمم، فحاور النبي علئوسلله اليهود والنصارى هله والمشركين وغيرهم كما بُين سابقاً، وكذلك دار الحوار مع الثقافات الأخرى عندما فتح المسلمون الفتوحات الإسلامية على مر التاريخ، فعندما دخل المسلمون هذه

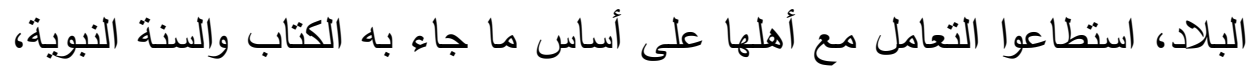

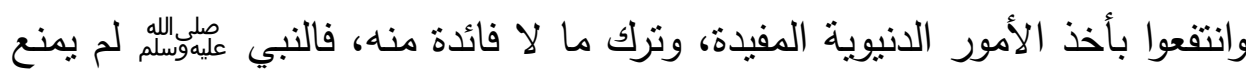
من التعايش السلمي مع غبر المسلمين حيث عاش في المدينة عليهوللهم ومعده اليهود أهل الذمة يبيعون ويشترون في الأسواق مع المسلمين، فعند البخاري رحمه الله عن أَبي هريرة رضي الله عنه قال:" بينما يهودي يعرض سلعته أعطي بها شيئًا كرهه فقال لا والذي اصطفى موسى على البشر فسمعه رجل من الأنصار فقام فلطم وجهه وقال: تقول والذي اصطفى موسى على البشر والنبي عليهولسلم بين أظهرنا فذهب إليه فقال: أبا القاسم إن لي ذمة وعهدا فما بال فلان لطم وجهي فقال: لم لطمت وجها فذكره فغضب النبي عليهولاللم حتى رئي في وجهه ثم قال لا تفضلوا بين أنبياء اله "(()، فالإسلام قد ركز على التعايش السلمي بين أهل الأديان، وكما أن

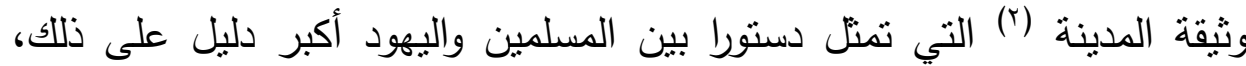

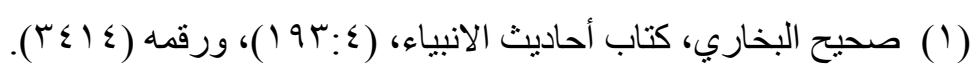

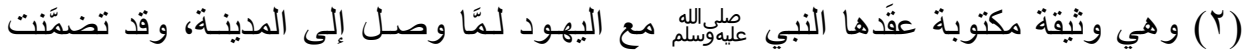

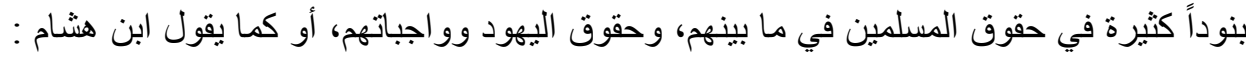

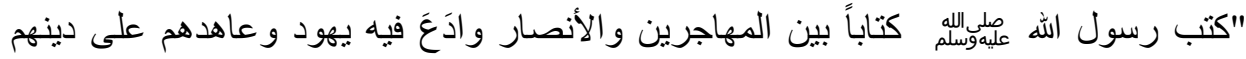

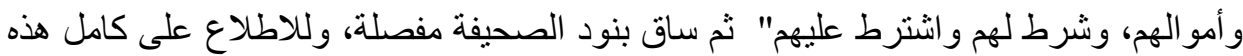

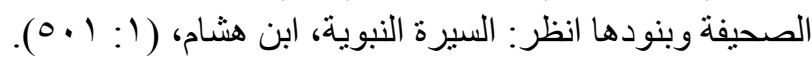

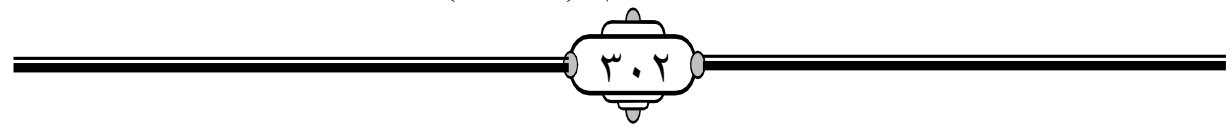


فبهذا التعايش كان لزاماً أن يكون هناك حوار فكري بين الإسلام وغيره من الثقافات والحضارات، ولا بد أن يكون هذا الحوار مبني على التوسط والاعتدال ومن مظاهر هذا التوسط العدل والإنصاف، وهاتان الخصلتان من أهم خصال الدين التي تبين لنا عظمته؛ حيث أوجب الله عز وجل العدل والإنصاف في جميع مناحي وجوانب هذا الدين وشرائعه وأحكامه، حتى وإن كان ممن يخالفلك في الدين والعقيدة، والحوار إحدى هذه الجوانب التي أوجبت الثريعة فيها العدل والإنصاف، وإلا اضطربت الأحوال وفسدت الآراء فقد جاءت نصوص كثثرة في كتاب الله وسنة نبيه

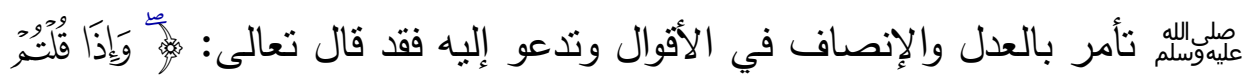

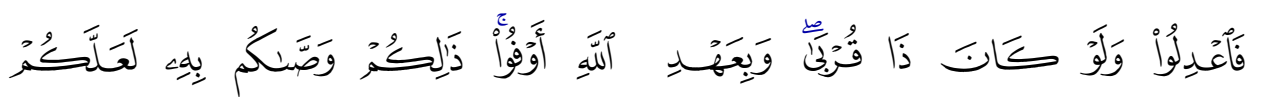

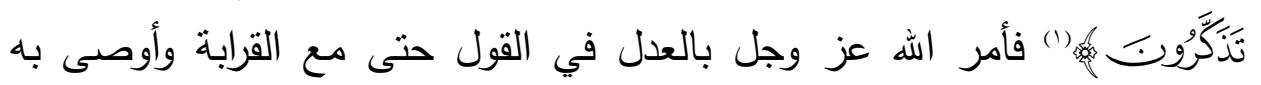

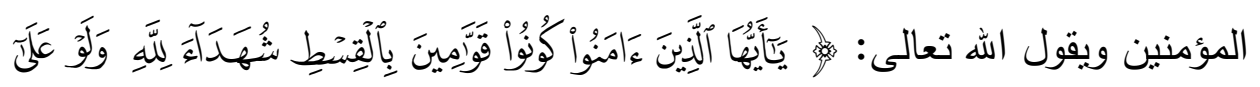

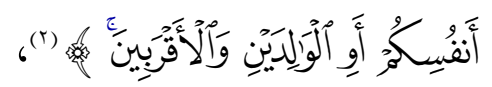

وبهذا بتبين أن من أهم مظاهر الوسطية الفكرية في الحوار الحضاري أنه قائم على العدل والإنصاف وعدم غمط المخالف حقه وأن تكون معاملته بالعدل. ومن تللك المظاهر أن الوسطية الفكرية في الحوار الحضاري قائمة على الرحمة ومحبة الخير للناس، وهذه سمة ظاهرة من السمات التي تتميز بها الوسطية في الحوار مع الثقافات والحضارات الأخرى، فالناظر في حوارات النبي عليولسلمه مع اليهود والنصارى وغيرهم يجد فيها حرص النبي عليهوللهم على محبة هداية القوم لا

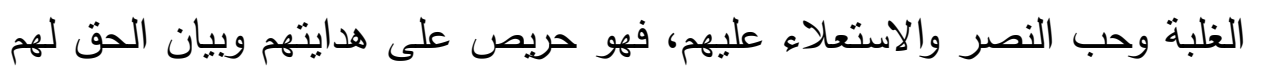
لإخراجهم من ظلمات الكفر إلى نور الإساد، وإنقاذهم من الوقوع في النار،

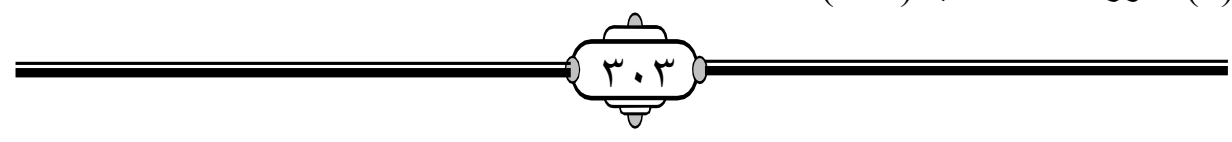


والأمتلة على ذلك من سيرته عليهولالله كثيره منها قصة الغلام اليهودي الذي كان يخدمه فلما غاب عن النبي عليهوللهم وعاده وجده على فراش الموت يلفظ أنفاسه

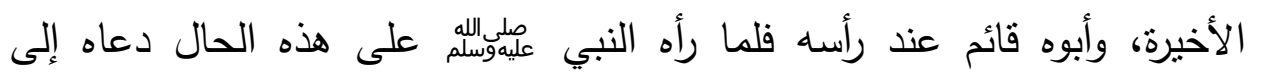
الإسلام والنطق بالثهادتين، فنظر الغلام في أبيه فقال له با بني أطع أبا القاسم

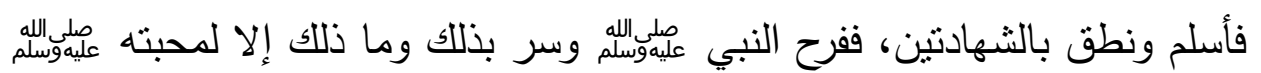
للخير ولهداية الناس، فعن أنس ، رضي الله عنه ، قال :" كان غلام يهودي يخدم النبي عليموسللم ، فمرض ، فأتاه النبي عليلوسلمه يعوده ، فقعد عند رأسه ، فقال له: أسلم ، فنظر إلى أبيه وهو عنده، فقال له: أطع أبا القاسم عليهوسلم ، فأسلم ، فخرج النبي عليولسلم وهو يقول: الحمد لله الذي أنقذه من النار " (').

ومن مظاهر الوسطية الفكرية في الحوار الالتزام بالخلق الحسن في التعامل مع المخالف، فالأخلاق الحسنة لها أهمية بالغة في الإسلام، وهي منظومة منكاملة جعلها الإسلام منهج حياة أمر بها وحض عليها وامتدح أهلها وأنثى عليهح فقد قال عليهولسلمه: "إن أحبَّكم إليَّة، وأقربكم مني في الآخرة مجلسمًا، أحاسنُكم أخلاقًا، وإن

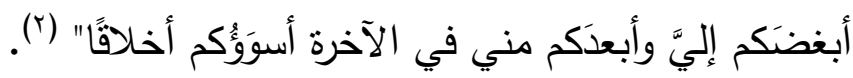
فامتثال الأخلاق الحسنة في الحوار يستطيع المحاور من خلاله أن يؤثز في النفوس لتباع الحق، وأمثلة ذلك في الكتاب العزيز كثيرة منها ما كان بين نبي الله موسى عليه السلام وفرعون الذي كان أعتى أهل زمانه وأفسقهم وأفسدهم حيث إدعى الربوبية وألحق ببني إسرائيل أثند العذاب وقتل أبنائهم، ومع ما كان منه إلا

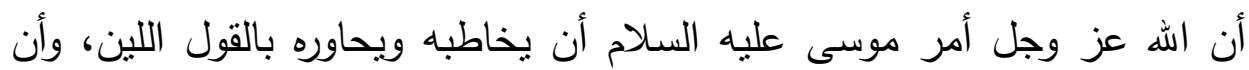

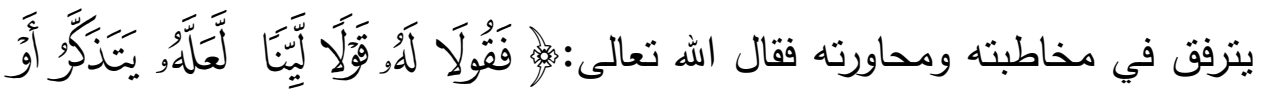

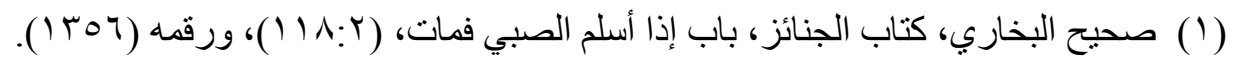

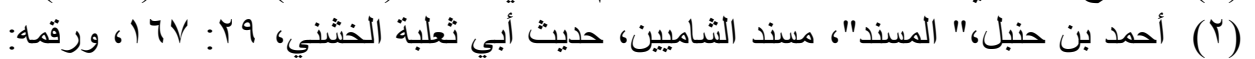

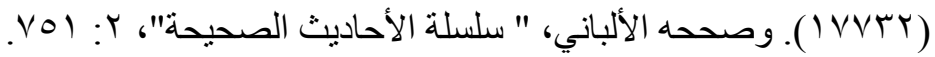

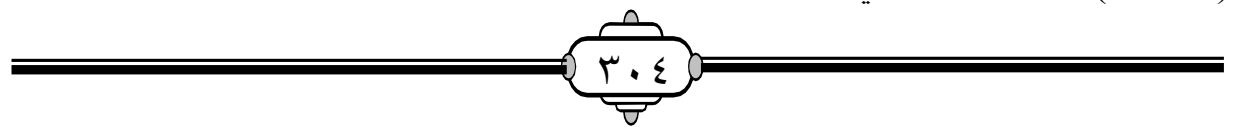




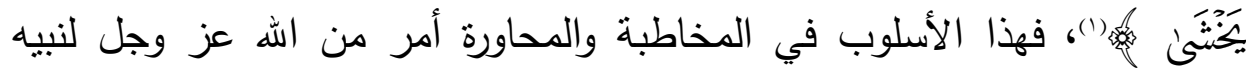

موسى عليه السلام مع علمه سبحانه وتعالى حال فرعون ورده، كل ذللك ليثبت لنا أهمية مراعات محاسن الأخلاق في الحوار وأن هذا يعد سمة ظاهرة من مظاهر • الوسطية في الحوار

\section{المطلب الثالث}

آثار الوسطية الفكرية في الحوار الحضاري.

إن آنار الوسطية في الحوار الحضاري ونتائجه المتوخاة من تطبيقها ونشر هذه الثقافة قولاً وعملاً كثيرة، سواء كان ذلك على مستوى الأفراد أو على مستوى النى (1) (1) سورة طه، الآية (ع ).

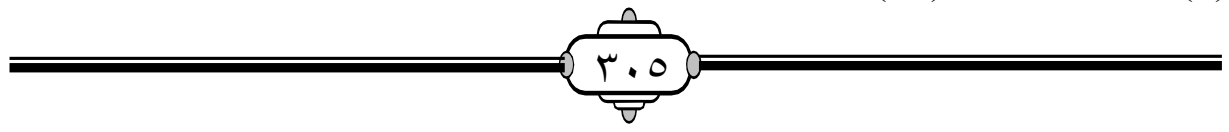


المجتمات لا سيما أن الوسطية الفكرية في الحوار الحضاري شبه مفقودة في الحوارات والتعاملات القائمة في هذه الأزمان، فكثير من حوارات اليوم قائمة على التعصب ونبذ الأخر، لكن الوسطية في الحوار منهج شرعي قائمة على أصول وأسس ربانية المصدر يجب أن يُتعامل بها في كل الحوارات الحضارية القائمة بين الثقافات والحضارات المختلفة، وهي حق لكل صاحب رأي أو موقف مخالف، ومن لا يطبق ذلك في حواراته فقد خالف الكتاب العزيز وهدي النبي عليهوليلم، فالآثار والنتائج المرجوة من نشر ثقافة الوسطية في الحوار كفيلة بمد جسور التقارب والتلاقي والتعاون والتكاتق بين البشر، وخاصة من يشتركون في دين واحد ويجتمعون على سنة وهدي نبي واحد ولديهم نراث إسلامي عظيم بناه وصنعه أئمة

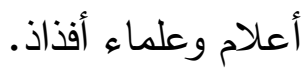

ومن تللك الآثار وأعظمها هو انتشار الإسلام وظهور جماله وروعته، فعندما يكون الحوار قائم على الوسطية والاعتدال، ويتحلى المحاور بهذا الخلق الذي يعد من مكارم ومحاسن الأخلاق، عند ذللك يرى الطرف الأخر هذا الإنصاف والاعتدال بصورة مشرقة؛ فيكون بذلك من أعظم وأكبر أسباب قبول الحق والدخول

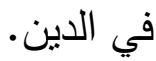

ومن هذه الآثار الناتجة عن تطبيق الوسطية في الحوار نبذ العصبية وتقبل الآخر، فإذا كان الحوار قائم على التوسط والاعتدال كلما كان أبعد عن التعصب

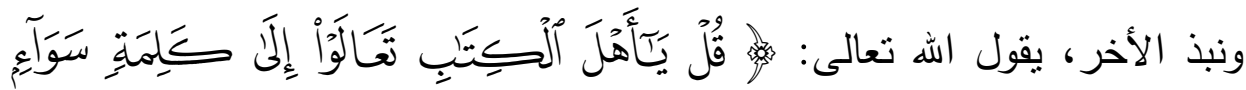

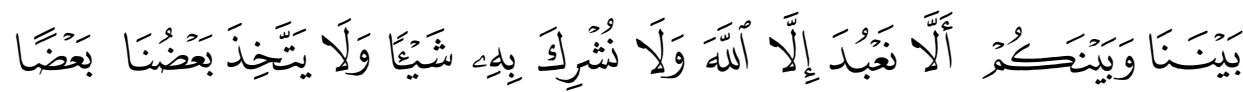

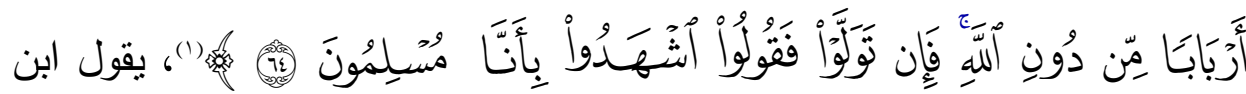




\section{الوسطية الفكرية وأثرها في الحوار الحضاري المعاصرل}

كثير رحمه الله: " هذا الخطاب يعم أهل الكتاب من اليهود والنصارى، ومن جرى مجراهم، والكلمة السواء أي: عدل ونصف، نستوي نحن وأنتم فيها" ('). كما أن الوسطية في الحوار لها الأثر البالغ في قلَّة الخطأ، وكثرة الصواب، فإذا سلك المتحاور هذا المسلك فإن من بركات ثللك الوسطية البعد عن الوقوع في

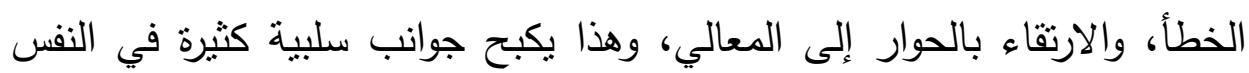
البشرية، تدور بين الإفراط والتقريط؛ كالكِبر ، والغرور، والرياء، الذي قد يوصل إلى الغلو، والتتطع الممقوت، ويُيعد عن التوسط والاعتدال.

كما أنه لا يخفى ما للوسطية في لحوار من أثز إيجابي في تحصين النشء عن الانحراف الفكري، وله أثره في بناءِ العلاقات وجمع الكلمة ونبذ الفرقة والتتازع، وله دوره في إعمال الفكِر والتفكير الذي أوصى به الله جل جلاله. 
أحمد الله جلالهل أن منَّ بإتمام هذه الدراسة، أحمده حمداً كثيراً على ما أنعم به وتفضل، وأسأله سبحانه أن يتقبله ويجعله نافعاً مفيداً لي، وللإسلام والمسلمين هده وأن يعفو عمّا حصل فيه من تقصير وخلل وخطأ، إنه سميع قربب مجيب. وبعد؛ فقد تتاولت في ثتايا مباحث ومطالب هذه الدراسة موضوع: " الوسطية الفكرية وأثرها في الحوار الحضاري المعاصر"

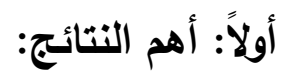
هناك جملة من النتائج التي توصل لها الباحث من خلال دراسته لهذا الموضوع

أولاً: أهمية الدعوة إلى الوسطية في الحوار الحضاري المعاصر ، وتربية الأفراد والمجتمعات عليها، خاصة وأن العالم أصبح الآن أثبه بالقربة الصغيرة بفضل التقدم التقني والثثرة المعلوماتية الحديثة فأصبح التواصل بين الثعوب والثقافات والحضارات أسهل من ذي قبل، فبهذه الوسطية يؤتي الحوار الثمار المرجوة منه بما يخدم إيصال الحق والتعايش السلمي بين التقافات المختلفة. ثانياً: أن الوسطية في الحوار الحضاري حاجة إنسانية؛ لأنها تؤدي إلى الانفتاح والتواصل مع التقافات الإنسانية، فالاعتدال والوسطية يمنعان من الانعزال والانكفاء والاستغناء عن الآخر، ويؤديان إلى التفاعل معه، والانفتاح على التقافات والتواصل الإنساني.

ثالثاً: أن من أهم ضوابط الوسطية الفكرية في الحوار الحضاري المعاصر اعتمادها على أصلين عظيمين وهما ما جاء في الكتاب العزبز والسنة النبوية وموافقتهما لذلك.

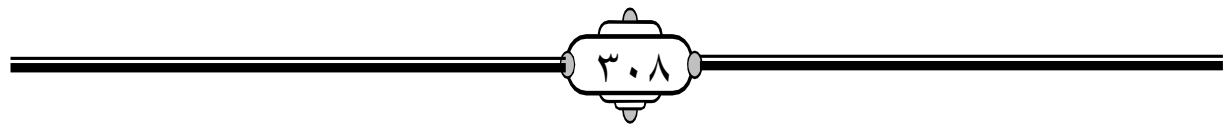




\section{الوسطية الفكرية وأثرها في الحوار الحضاري المعاصرح}

رابعاً: أن الوسطية الفكرية في الحوار المعاصر نؤدي إلى حسن التصرف وسلامة السلوك من الانحراف.

خامساً: أن من أهم أصول الوسطية في الحوار الحضاري التجرد في طلب الحق، والحذر من التعصب والهوى.

سادساً: وجوب التزام منهج السلف الصالح في الوسطية في الحوار؛ لأنه المنهج الحق الذي لا يغلب جانب على جانب، ولا يضيع حق مقابل حق آخر .

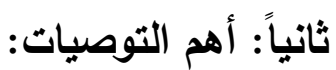

أولاً: ضرورة توعية الأفراد والمجتمعات بأهمية الوسطية في الحوار، وحث المجتمعات على التمسك بها وتطبيقها.

ثانياً: عقد مؤتمرات وندوات علمية للتوعية بأهمية الوسطية في الحوار، ودراسة المسائل التي تهم أطراف الحوار فيما بخدم الاستقرار والاحترام المتبادل وفق ضوابط الثربعة الإسلامية.

ثالثاً: إنشاء مراكز علمية متخصصة لرعاية الوسطية الفكرية في الحوار الحضاري المعاصر لتحقيق هذه الوسطية وتعزبزها.

رابعاً: طباعة الكتب التي تحذر من العصبية والغلو وتثعو إلى التوسط والاعتدال ونشرها.

خامساً: الاستفادة من وسائل التقنية الحديثة لتفعيل الحوار الوسطي بين التقافات والحضارات المختلفة.

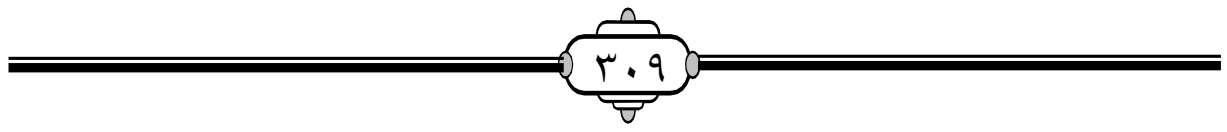




\section{قائمة المصادر والمراجع}

1- أصول الحوار وآدابه في الإسلام، صالح ابن حميد، (ط (، الرياض، دار

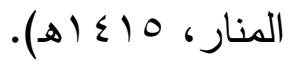

r-بلوغ الآمال في تحقيق الوسطية والاعتدال، عبدالرحمن السديس، (طس،

$$
\text { الرياض، مدار الوطن للنشر، مبع (هـ). }
$$

r- تذكرة السامع والمتكلم في أدب العالم والمتعلم، ابن جماعة، (ط ا، بيروت،

$$
\text { دار البشائر ، } 1 \text {. . ب بم). }
$$

ع - تقسير القرآن العظيم، ابن كثثر، تحقيق: سامي بن محمد سلامة، (طب،

$$
\text { الرياض، دار طيبة للنشر والتوزيع، · بـ (هـ). }
$$

ه- جامع البيان في تأويل القرآن، محمد بن جرير الطبري، تحقيق: أحمد

$$
\text { محمد شاكر ، (ط ا، الرياض، مؤسسة الرسالة، . . . rم). }
$$

צ- الجامع لأحكام القرآن، القرطبي، محمد بن أحمد، تحقيق: أحمد البردوني

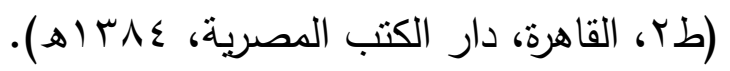

V- حقيقة الفكر الإسلامي، أبو زيد عبد الرحمن، (ط ا، الرياض، دار المسلم،

$$
\text { (ه) } \leqslant 10
$$

1- الحوار آدابه وضوابطه في ضوء الكتاب والسنة، يحي زمزمي، (ط ا، دار

$$
\text { التراث والتربية، ع ( ؛ (هـ). }
$$

9- حوار الحضارات المفهوم والمقومات، عبدالملك المصعبي، (ط (، تونس،

$$
\text { مركز الدراسات للنشر ، } 0 \text {. . rم). }
$$

• - - سلسلة الأحاديث الصحيحة، الألباني، محمد بن ناصر الدين،

$$
\text { (ط (، الرياض، مكتبة المعارف، ؟ . . rم).) }
$$

11- - السيرة النبوية، ابن هشام، عبدالملك بن هشام، تحقيق: مصطفى

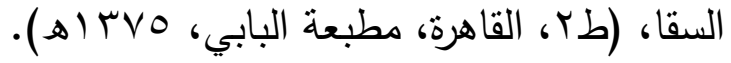

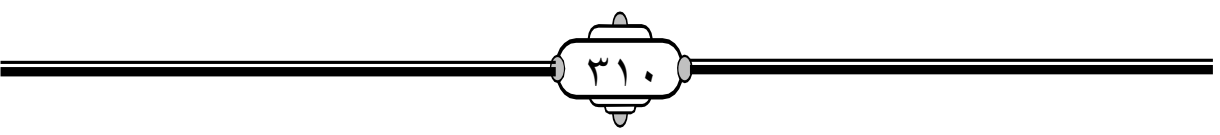


r ا - صحيح البخاري، البخاري، محمد بن إسماعيل، تحقيق: محمد زهير الناصر، (ط ا، الرياض، دار طوق النجاة، بr (هـ).

r - - صحيح مسلم، النيسابوري، مسلم بن الحجاج، تحقيق: نظر محمد

$$
\text { الفاريابي. (ط (، دار طيبة، و ع أهـ). }
$$

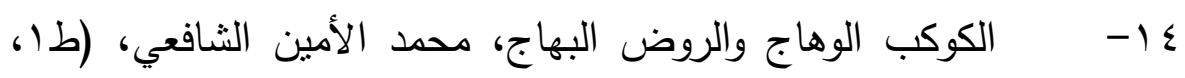

$$
\text { الرياض، دار طوق النجاة، } 9 \text {. . rم). }
$$

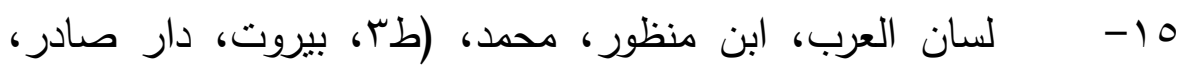

$$
\text { (ه) }(\$) \leq
$$

7 1 - مجموع الفتاوي، ابن تيمية، تحقيق: أنور الباز وعامر الجزار،

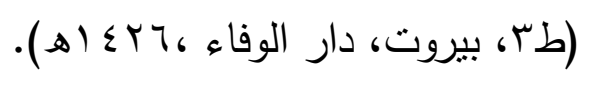

المجموع شرح المهذب، النووي، تحقيق: محمد نجيب، (ط ا، جده،

$$
\text { مكتبة الإرشاد). }
$$

11 - - المسند، الثيباني، أحمد بن حنبل، تحقيق: شعيب الأرنؤوط

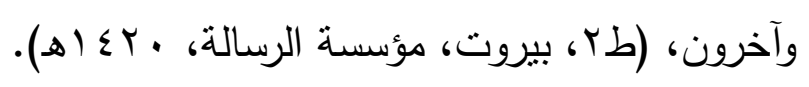

19- معالم التنزيل في تقسير القرآن، البغوي، الحسن بن مسعود، تحقيق: عبد الرزاق المهدي، (طا، بيروت، دار إحياء التراث العربي،

$$
\text { (ه) } \leqslant \text { (ه. }
$$

• النمر ، (طء، الرياض، دار طيبة للنشر والتوزيع، و99 1 م).

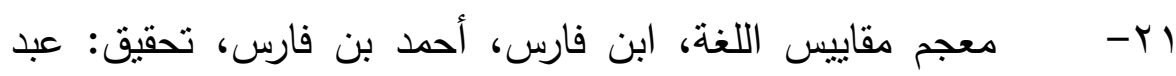

$$
\text { السلام هارون (ط ا، بيروت، دار الفكر، و9 ب اهـ). }
$$

ץY- المفردات في غريب القرآن، الأصفهاني، الحسن بن محمد، تحقيق: صفوان الداودي (ط ا، بيروت، دار القلم، r آـ اهـ).

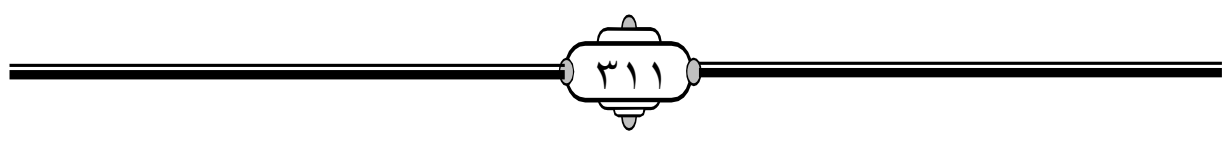


ב- الوسطية الفكرية وأثرها في الحوار الحضاري المعاصرت]

rr- من أجل حوار بين الحضارات، روجيه جارودي، ترجمة: د. ذوقان

قرقوط، (ط ا ، بيروت، دار النفائس، ا (1 ( هـ).

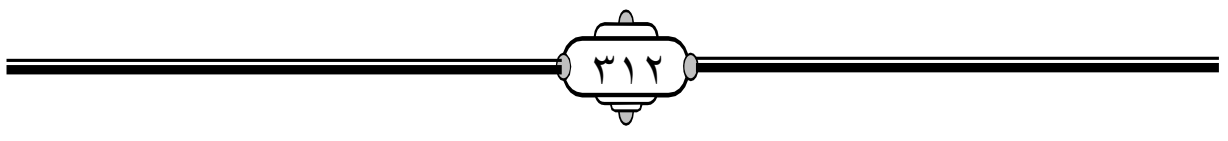

